\title{
The Influence of Cloud Feedbacks on Equatorial Atlantic Variability
}

\author{
Katinka Bellomo and Amy C. Clement \\ Rosenstiel School of Marine and Atmospheric Science, University of Miami, Miami, Florida \\ ThORSTEN MAUritsen, GABy RÄDEL, AND BJORN STEVENS \\ Max Planck Institute for Meteorology, Hamburg, Germany
}

(Manuscript received 11 July 2014, in final form 3 November 2014)

\begin{abstract}
Observations show that cloud feedback over the Namibian stratocumulus region is positive because cloud cover is anticorrelated with local sea surface temperature (SST) anomalies. Moreover, regressions of observed atmospheric fields on equatorial Atlantic SST anomalies indicate that cloud feedbacks over the Namibian stratocumulus region covary with Atlantic Niño. However, from observations alone, it is not possible to quantify the influence of regional cloud feedbacks on equatorial climate variability. To address this question, a set of sensitivity experiments are conducted using an atmospheric general circulation model (ECHAM6) coupled to a slab ocean in which the strength of positive cloud feedback is enhanced over several regions in the South Atlantic basin. Enhanced positive cloud feedback over the Namibian stratocumulus region increases local as well as equatorial SST variability, whereas enhanced cloud feedback over other regions in the South Atlantic increases local SST variability but exhibits negligible responses at the equator. The authors' results indicate that the Namibian region plays a central role in enhancing equatorial SST variability because it is located where the SST anomalies associated with the simulated Atlantic Niño in the slab-ocean model develop. These results highlight the important role of the regional coupling of cloud cover over the Namibian region with local SSTs and its effects on equatorial Atlantic climate variability.
\end{abstract}

\section{Introduction}

Equatorial Atlantic climate variability is dominated by a zonal mode of sea surface temperature (SST) anomalies occurring primarily during boreal summer (June-August) over the Atlantic cold tongue region $\left(6^{\circ} \mathrm{S}-2^{\circ} \mathrm{N}, 20^{\circ} \mathrm{W}-5^{\circ} \mathrm{E}\right)$. SST anomalies over the cold tongue are accompanied by changes in atmospheric and oceanic circulations that resemble those associated with El Niño-Southern Oscillation (ENSO) in the Pacific Ocean and have therefore been referred to as Atlantic Niño events (Merle 1980; Hisard 1980; Xie and Carton 2004). Atlantic Niños are characterized by warm anomalies along the equator and the eastern side of the South Atlantic Ocean (Ruiz-Barradas et al. 2000), weakening of equatorial trade winds west of $20^{\circ} \mathrm{W}$, and weakening of meridional winds associated with the

Corresponding author address: Katinka Bellomo, Rosenstiel School of Marine and Atmospheric Science, University of Miami, 4600 Rickenbacker Causeway, Miami, FL 33149.

E-mail: kbellomo@rsmas.miami.edu
North African summer monsoon to the east of $20^{\circ} \mathrm{W}$ (Horel et al. 1986; Zebiak 1993; Xie and Carton 2004). During warm Atlantic Niños, equatorial deep convection shifts southward (Wagner and da Silva 1994; Carton et al. 1996; Mitchell and Wallace 1992; Biasutti et al. 2003) and precipitation increases over the Gulf of Guinea (Hirst and Hastenrath 1983). Like their Pacific counterparts, Atlantic Niños have impacts on sea level, precipitation over surrounding continents, and fisheries (Brundrit 1995; Hagen et al. 2001; Boyer et al. 2001). For these reasons, understanding the origin, dynamics, and physical mechanisms of SST variability over the equatorial Atlantic is of primary importance to improve the predictability of Atlantic Niños and their impacts.

In addition to Atlantic Niño, previous studies have shown that equatorial Atlantic variability is affected by another dominant mode of variability: the decadal-timescale Atlantic meridional mode, which is characterized by asymmetric SST anomalies about the equator within the tropical Atlantic (e.g., Servain 1991; Servain et al. 1999; Nobre and Shukla 1996; Chang et al. 1997; Penland and Matrosova 1998; Tanimoto and Xie 2002; Chiang 
and Vimont 2004). However, because of possible statistical artifacts in the detection and interpretation of these modes of variability, it is still unclear whether the North Atlantic is correlated with Atlantic Niños and South Atlantic variability through the interhemispheric Atlantic meridional mode and on which time scales that mechanism operates (Mehta 1998; Enfield et al. 1999; Dommenget and Latif 2000). A number of studies suggest that the Atlantic meridional mode does not arise as a mode of variability after the rotation of the first leading empirical orthogonal functions (EOFs). In fact, the first two leading rotated EOFs are each confined to one hemisphere with little projection on the other hemisphere (Houghton and Tourre 1992; Dommenget and Latif 2000; Trzaska et al. 2007).

The Atlantic cold tongue is more influenced by the South Atlantic because of the geometry of the African continent and because the climatological position of the ITCZ in the Northern Hemisphere predominantly drives surface cross-equatorial flow from the south to the north, which means that perturbations in the trade winds in the Northern Hemisphere have relatively little influence on equatorial SSTs (cf. Okumura 2013; Zhang et al. 2014; Bellomo et al. 2014a). For these reasons, it is argued that Atlantic equatorial variability is more strongly influenced by South Atlantic rather than North Atlantic SST variability (Dommenget and Latif 2000; Trzaska et al. 2007).

Several studies have shown connections between the subtropical and extratropical South Atlantic and equatorial Atlantic variability (Venegas et al. 1996; Robertson et al. 2003, Barreiro et al. 2004). These can be divided into studies that argue for a fundamental role for oceanic processes and ocean waves (e.g., Zebiak 1993; Carton et al. 1996; Delecluse et al. 1994; Servain et al. 1999; Sutton et al. 2000; Florenchie et al. 2003, 2004) and studies that contend that thermodynamic feedbacks involving the interaction of atmospheric circulation, latent heat flux, and cloud cover can alone explain tropical Atlantic variability and, to the first order, Atlantic Niño (e.g., Dommenget and Latif 2000; Tanimoto and Xie 2002; Haarsma et al. 2003; Sterl and Hazeleger 2003; Chaves and Nobre 2004; Trzaska et al. 2007, Evan et al. 2013).

Dommenget and Latif (2000) used a hierarchy of models to show that a positive feedback among SST, wind stress, and latent heat flux at the surface is more important than ocean dynamics in driving upper-ocean tropical Atlantic variability. In addition, a number of studies, including Tanimoto and Xie (2002), Park et al. (2005), Trzaska et al. (2007), and Evan et al. (2013), have shown the importance of positive cloud feedbacks in increasing the persistence of SST anomalies over low-level cloud regions located off the coasts of Namibia. For example, Evan et al. (2013) estimated the influence of low-level cloud feedback from observations and then showed with an idealized coupled linear model that cloud feedbacks are necessary for the SST anomalies associated with the simulated Atlantic meridional mode to persist as long as it is observed.

Using observations, idealized climate models, and theoretical frameworks, these previous studies provide evidence that local coupling between SSTs and cloudiness can influence equatorial Atlantic variability. However, those studies do not evaluate the impacts of cloud feedbacks relative to other atmospheric or oceanic processes or the influence of cloud feedbacks from different regions over the South Atlantic basin. To address these questions, we use an atmospheric general circulation model (ECHAM6) coupled to a slab ocean in which we artificially increase the strength of positive cloud feedback over selected regions. First, we investigate the role of cloud feedbacks over the Namibian stratocumulus region in modulating the persistence of local and equatorial SST variability, and then we evaluate the influence of cloud feedbacks from other regions in the South Atlantic on equatorial SST variability.

\section{Data and methods}

\section{a. Observations}

We use monthly-mean values of SST from the Extended Reconstructed SST, version 3b (ERSSTv3b) reanalysis (Smith et al. 2008) along with surface winds and sea level pressure (SLP) from the NCEP-NCAR reanalysis (Kalnay et al. 1996). Observed cloud feedback is estimated using cloud cover and cloud radiative effect (CRE). We use monthly-mean values of cloud cover from the International Satellite Cloud Climatology Project (ISCCP; Rossow and Schiffer 1999) for the years 1984-2007 and seasonal-mean values of cloud cover from the Extended Edited Cloud Reports Archive (EECRA; Hahn and Warren 2009) for the years 19542008. Monthly-mean values of CRE are from the Clouds and Earth's Radiant Energy System (CERES) Energy Balanced and Filled, edition 2.7 (EBAF_Ed2.7) dataset for the years 2001-10 (Loeb et al. 2009) and from ISCCP for the years 1984-2007.

We detrend all observational data by removing the least squares regression line and compute monthlymean anomalies by subtracting the long-term monthly mean from each calendar month. For cloud data from EECRA, we compute seasonal-mean anomalies subtracting the long-term seasonal mean from each season. Observational datasets are affected by observational 
errors. In satellite data, errors are mostly caused by replacement of instruments and orbital drifts over time. Instead, in ship-based data errors arise because of unknown observational artifacts that introduce a spurious trend in the tropical-mean long-term variability. This trend is inconsistent with the observed increase in tropical-mean surface temperatures and satellite cloud datasets (Norris 2005; Eastman et al. 2011; Clement et al. 2009). For these reasons, all cloud datasets were corrected for presumed spurious artifacts by removing tropical-mean variability (cf. Bellomo et al. 2014b). We note that these artifacts mostly affect estimates of longterm trends in cloud cover, whereas we are interested in detrended interannual to decadal-time-scale climate variability.

\section{b. Model experiments}

To test the role of positive cloud feedbacks on Atlantic climate variability, we perform model experiments using a state-of-the-art AGCM (ECHAM6, version 6.1.04) coupled to slab ocean for the open ocean and a thermodynamical sea ice model (Stevens et al. 2013). We use the coarse-resolution ECHAM6 (ECHAM6-CR) with T31 horizontal grid $\left(3.75^{\circ} \times 3.75^{\circ}\right)$ and 31 vertical levels. The mixed layer depth of the slab-ocean model is fixed to $50 \mathrm{~m}$ everywhere and does not vary seasonally.

In the slab-ocean configuration, interactive ocean dynamics are absent and internal climate variability is driven solely by the thermal coupling between the ocean and the atmosphere (i.e., shortwave and longwave radiation plus latent and sensible heat fluxes). The monthly climatology of ocean heat transport (commonly referred to as $q$ flux) is prescribed to maintain the SST climatological mean but does not vary from year to year. For all experiments, the $q$ flux is obtained from a control simulation using the AGCM with fixed climatological monthly-mean SSTs computed from observations.

We perform a control simulation using the prescription of phase 5 of the Coupled Model Intercomparison Project (CMIP5) preindustrial control experiments (Taylor et al. 2012), which we compare with model experiments in which we increase the strength of local positive cloud feedbacks. To increase the strength of positive cloud feedback, we use the experimental design of Bellomo et al. (2014a). Following their methods, we multiply cloud liquid water in the radiation module by an amplifying factor $y$, which is a function of underlying SST anomalies,

$$
y=1-\arctan (\mathrm{SST}) 2 / \pi .
$$

In the equation above, SST indicates local SST anomalies computed as SST in the current run minus SST monthly-mean climatology computed from a control simulation. Equation (1) is applied at each time step of the model simulation and at each grid point where we increase the strength of local positive cloud feedback. In this study, positive feedback means a reduction (increase) in cloud radiative effect when the underlying SST anomaly is warm (cold). Further details of the model setup are provided in Bellomo et al. (2014a).

We perform a first experiment in which cloud feedback is enhanced in the subtropical South Atlantic where the mean subsidence at $500 \mathrm{hPa}$ is greater than $10 \mathrm{hPa} \mathrm{day}^{-1}$ and the mean lower-tropospheric stability (LTS) is greater than $16.5 \mathrm{~K}$ (LTS is defined as the difference in potential temperature at $700 \mathrm{hPa}$ and the surface). These criteria are chosen to target regions in which subtropical stratocumulus clouds predominate in the model (Medeiros and Stevens 2011). The box in which these constraints are met in the model is highlighted in red in Fig. 1 and corresponds to the Namibian stratocumulus region (Klein and Hartmann 1993). Hereafter, we will refer to the experiment that enhances cloud feedbacks in this region as the Namib simulation. Both the control and the Namib simulations are run for $200 \mathrm{yr}$.

To investigate the role of cloud feedbacks over other South Atlantic regions, we perform a series of sensitivity experiments in which we enhance the strength of positive cloud feedback in nine regions located within $5^{\circ} \mathrm{N}-$ $30^{\circ} \mathrm{S}, 40^{\circ} \mathrm{W}-10^{\circ} \mathrm{E}$. These experiments are named according to the number in the black boxes in Fig. 1 (e.g., "box 1," "box 2"), where we note that box 6 is a subset of the Namib experiment. We run all sensitivity experiments for a period of $100 \mathrm{yr}$. The length of these simulations is constrained by computational resources but is deemed sufficient because an analysis of $80 \mathrm{yr}$ instead of $180 \mathrm{yr}$ in the control and Namib experiments leads to qualitatively similar results. The analysis of the nine experiments in the boxes motivated longer simulations for boxes 3 and 6 , which were run for an additional $50 \mathrm{yr}$ (i.e., a total of $150 \mathrm{yr}$ of simulation time). We use these longer experiments to further characterize the influence of these regions on low-frequency equatorial variability.

For all experiments, we discard the first $20 \mathrm{yr}$ of spinup time from the analysis to remove the possible influence of the initial conditions, and we compute monthly-mean anomalies by removing the simulated annual cycle from each month. For all slab-ocean experiments shown in this paper, we find that the global-mean change in SST from the control simulation is negligible (on the order of $\sim 0.01 \mathrm{~K}$ ). Moreover, Bellomo et al. (2014a) showed that changes in the mean climate do not affect the changes in internal climate variability caused by enhanced cloud feedbacks or the simulation of the seasonal cycle of SST. 


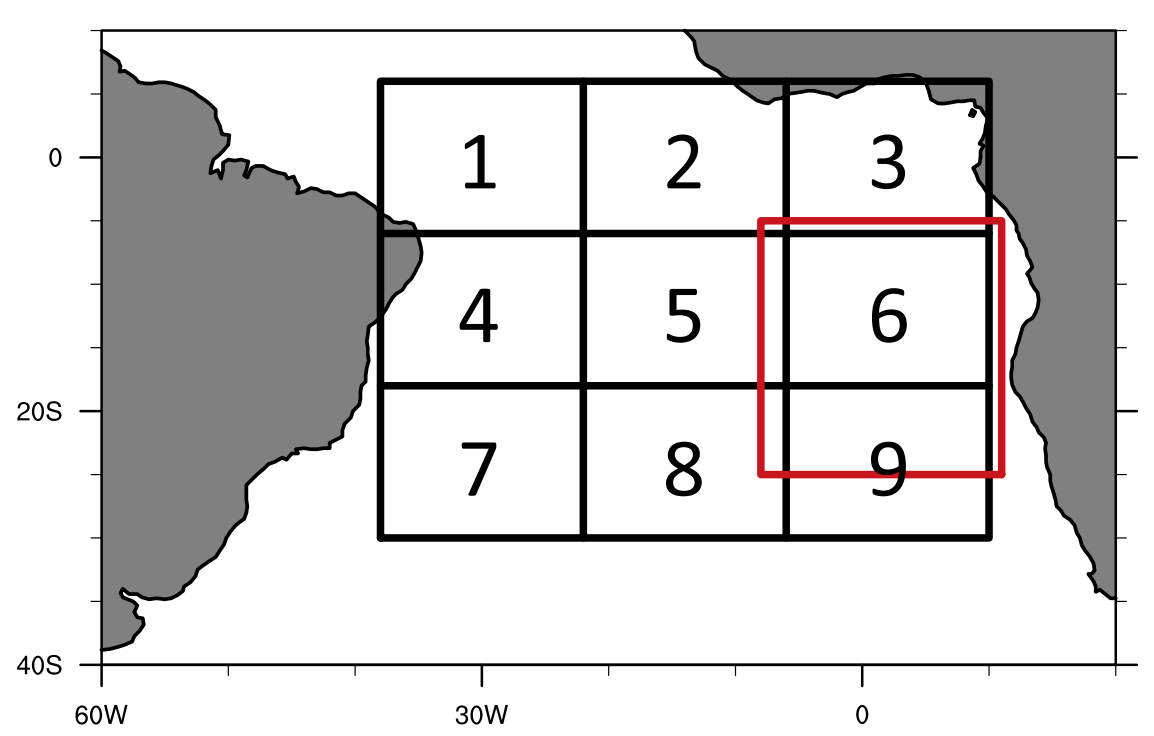

FIG. 1. Masking used in the model experiments with enhanced positive cloud feedback. The red box is the Namib experiment, and the black boxes 1-9 are regional experiments in the South Atlantic.

\section{Results}

\section{a. Observations}

Figure 2 shows the regressions of observed local SST anomalies (shaded), SLP (contours), and surface winds (vectors) on an equatorial Atlantic (Atl3) index for the years $1960-2010$. The Atl3 index $\left(5^{\circ} \mathrm{S}-5^{\circ} \mathrm{N}, 20^{\circ} \mathrm{W}-0^{\circ}\right)$, which is highlighted by the black box in Fig. 2, is commonly used to measure Atlantic Niño activity. Stippling in Fig. 2 indicates where the linear correlation of SST with the At13 index is statistically significant at the $95 \%$ level of a Pearson's $r$ test for correlations.

The regression in Fig. 2 displays a zonal mode along the equator: the Atlantic Niño. Atlantic Niño is accompanied by large anomalies in the strength of trade winds along the equator and northerly wind anomalies crossing the equator (Fig. 2). A weakening of SLP and wind circulation around the subtropical high is evident in the South Atlantic. Atlantic Niño is correlated with SST anomalies of the same sign in the southeastern part of the South Atlantic Ocean and with SST of opposite sign in the southwest. It is noteworthy that Atlantic Niño SST anomalies are significantly correlated with SSTs in the South Atlantic Ocean (stippling in Fig. 2) but not correlated with North Atlantic SSTs, suggesting that Atlantic Niños are influenced by South Atlantic SSTs but not by North Atlantic SSTs and the Atlantic meridional mode (see discussion in Marshall et al. 2001).

Atlantic Niño is also accompanied by changes in cloud cover, which influence the radiation budget at the surface. To calculate the anomalies in the net radiation budget at the surface due to changes in cloud cover, we estimate cloud amount feedback as defined in Bellomo et al. (2014b) from observations. To estimate cloud amount feedback, we first divide climatologicalmean net (i.e., longwave plus shortwave) CRE by climatological-mean total cloud amount, where CRE is computed as the difference between total-sky and clearsky radiation fluxes at the surface. This ratio is called the cloud amount radiative kernel $(k)$, as in Bellomo et al. (2014b), and represents the sensitivity of CRE to changes in mean cloud amount (units of $\mathrm{W} \mathrm{m}^{-2} \%^{-1}$ ),

$$
k=\frac{\overline{\mathrm{CRE}}}{\bar{C}} .
$$

Cloud amount radiative kernel is computed using radiative fluxes from CERES using the years 2001-09 and all years available for cloud data in the two cloud datasets. Then, we multiply the cloud amount radiative kernel [Eq. (2)] by the regression of total cloud amount on the At13 SST index anomalies to obtain the regression of cloud amount feedback on the Atl3 SST index (units of $\mathrm{W} \mathrm{m}^{-2} \mathrm{~K}^{-1}$ ). As discussed in Bellomo et al. (2014b), cloud amount feedback as estimated here does not take into account perturbations in cloud vertical and optical properties and should be interpreted as the cloud amount component of the total cloud feedback, which can be written as the sum of cloud amount, cloud altitude, cloud optical feedbacks, and a residual term (Zelinka et al. 2012). We note that this cloud amount feedback includes all cloud types. 


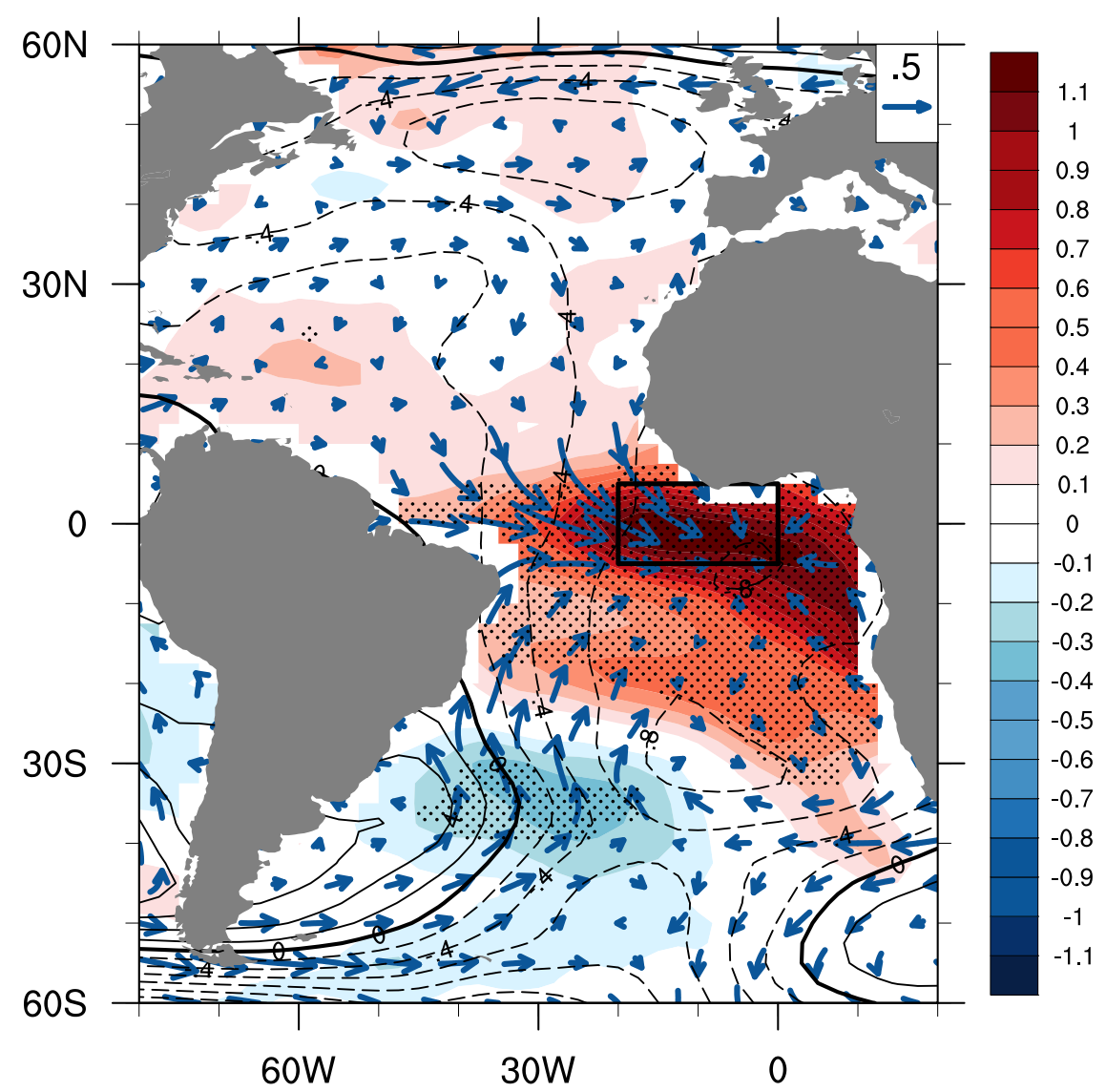

FIG. 2. Regression of observed SST (shaded), SLP (contours), and surface winds (vectors) on the At13 SST index (black box) for the years 1960-2010. Contours are from -2.0 to $2.0 \mathrm{hPa}$ with an interval of $0.2 \mathrm{hPa}$. Solid lines refer to positive SLP anomalies, dashed lines refer to negative SLP anomalies, and the thick solid line is the zero-level contour. Stippling indicates where the correlation between local SSTs and the Atl3 SST index is statistically significant at the $95 \%$ level of the Pearson's $r$ test for correlations. All data are detrended.

The regressions of cloud amount feedback on Atl3 SST index are shown in Fig. 3. Figure 3a is obtained using cloud data from ISCCP for the years 1984-2007, while Fig. 3 b is obtained using cloud data from EECRA for the years 1954-2008. These regressions represent the net radiation anomaly at the surface that is due to changes in cloud cover associated with Atlantic Niño SST fluctuations. Changes in cloud cover (contours) display a decrease in the eastern part of the South Atlantic, which is mostly covered by low-level stratocumulus clouds, and an increase in cloud cover in the western equatorial Atlantic, where deep-convective clouds predominate (Norris 1998). The decrease in low-level clouds in the eastern part of the basin associated with warm SST anomalies in the Atl3 region is interpreted as a positive cloud amount feedback (shaded) that further amplifies SST anomalies (cf. Evan et al. 2013). In contrast, the increase in deep-convective clouds in the western equatorial Atlantic is interpreted as a negative cloud amount feedback, which damps underlying warm SST anomalies (Fig. 2). Therefore, a positive cloud feedback associated with low-level clouds in the eastern part of the basin promote the persistence of SST anomalies associated with the Atl3 region (Fig. 2), whereas negative cloud feedback due to deep-convective clouds in the western equatorial Atlantic damps SST anomalies.

The negative values of the regression of cloud amount feedback on Atl3 SST index found over the southwestern part of the basin (Fig. 3) also represent a positive cloud feedback because SST anomalies are negative in this region when Atl3 anomalies are positive (cf. Fig. 2). That is, cooler SSTs over the southwestern South Atlantic are associated with more cloud cover (contours) and hence less radiation into the surface. Observations from ships (Fig. 3b) are coarser and sparser but also resemble the large spatial pattern seen from satellites (Fig. 3a). Most importantly, they show that these 

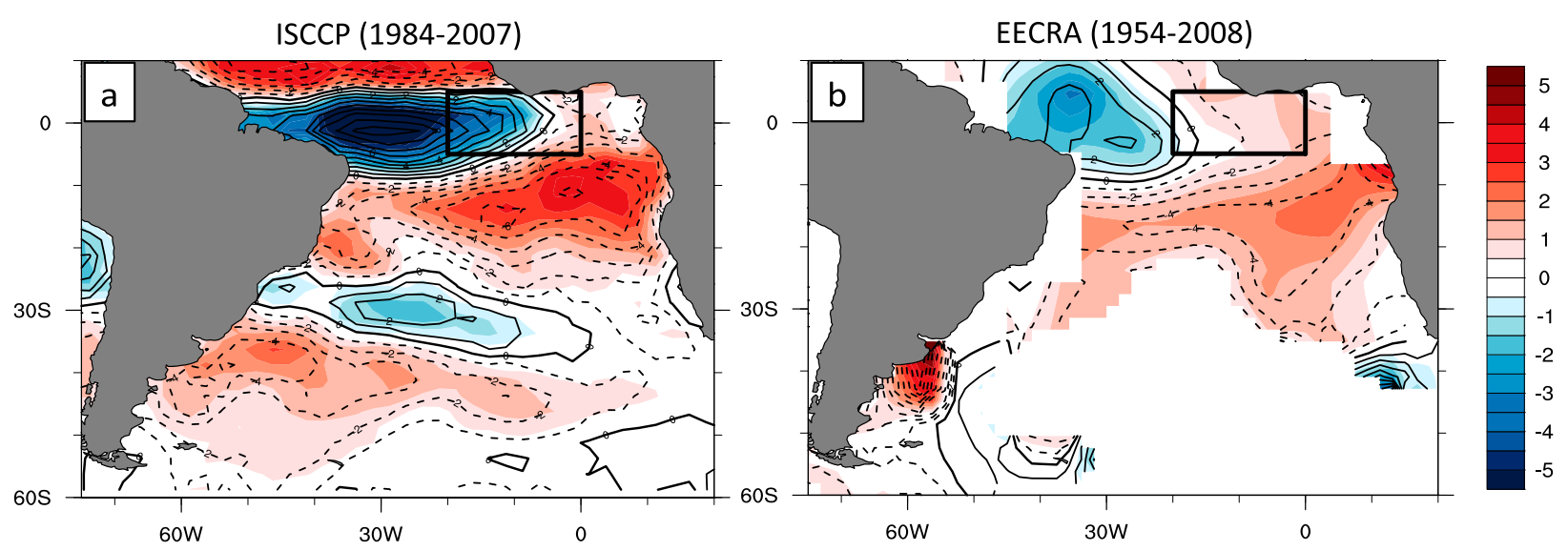

FIG. 3. Regressions on the Atl3 index (black box) of cloud amount feedback (shaded; units of $\mathrm{W} \mathrm{m}^{2} \mathrm{~K}^{-1}$ ) and cloud cover (contours; units of $\% \mathrm{~K}^{-1}$ ). Contour levels range from $-10 \%$ to $+10 \%$, with $1 \%$ interval. Solid lines indicate positive values, dashed lines indicate negative values, and solid thick lines indicate the zero level. (a) Cloud cover is from ISCCP (years 1984-2007). (b) Cloud cover is from EECRA (years 1954-2008). In this plot, we use interannual anomalies differently from all the other plots because the temporal resolution of EECRA is of seasonal monthly means.

changes in cloud cover are not particular to the satellite era, suggesting that they are not related to spurious trends or biases in the ISCCP dataset (Bellomo et al. 2014b).

Observations over the last six decades show that clouds covary with SST in the Atl3 region and with atmospheric large-scale circulation in a way that would amplify SST anomalies over the Namibian stratocumulus deck and the eastern equatorial basin. How does this cloud radiative forcing influence the variability of Atlantic Niño?

\section{b. Role of cloud feedbacks over the Namibian region}

To investigate the role of cloud feedbacks on Atlantic Niño and large-scale modes of climate variability, we run model experiments in which we enhance positive cloud feedback over the Namibian region, as outlined in section 2. Differently from observations, cloud feedback is estimated in model simulations as the regression of net CRE at the surface on local SST anomalies. This definition is different from the cloud amount feedback estimate shown for observations in Fig. 3 for two reasons: First, local cloud feedback is used now to highlight the response of the model to the imposed cloud liquid water-SST relationship [Eq. (1)], whereas the observed regressions in Fig. 3 show cloud radiative effect associated with anomalies in the Atl3 SST index to understand the variability associated with Atlantic Niño. Second, in the model we compute cloud feedback using radiative fluxes instead of cloud amount. We cannot use cloud amount as we do for observations because in this particular experimental design we do not change the coupling between cloud amount and SST but rather between
CRE and SST. Nevertheless, changing CRE in response to SST anomalies has the same effects as changing cloud amount. In fact, the regression of CRE on the Atl3 SST index using CRE from the short CERES dataset (200109) and from ISCCP (1984-2007) gives qualitatively similar results to those shown in Fig. 3 (not shown).

Figure 4a shows the difference in cloud feedback between the Namib experiment, in which we enhance positive cloud feedback over the Namibian stratocumulus region, and the control run. For comparison, Fig. $4 \mathrm{~b}$ shows cloud feedback in the control run. As intended, the model simulates stronger positive cloud feedback over the stratocumulus deck off the coasts of Namibia (Fig. 4a) where we enhance it (black box) and a decrease in the strength of cloud feedback in the equatorial regions due to dynamical adjustments in the model. The equatorial response in local cloud feedback to this remote forcing is not trivial. There is a strengthening of the negative feedback in the west and a weakening of the positive feedback in the east. Either way, the overall effect of the imposed enhanced local feedback in the Namib region is to increase the local cloud radiative damping of SST (i.e., more negative cloud feedback) in the equatorial region.

The imposed relationship of cloud liquid water to SST [Eq. (1)] in the Namib experiment makes the model simulation of cloud feedback more similar to observations. In the control simulation (Fig. 4b), cloud feedback is underestimated over the Namibian region and overestimated over the equator, where observations show cloud feedback of negative sign while in the model the sign is positive (cf. Evan et al. 2013, and references therein). In the Namib experiment, cloud feedback over 

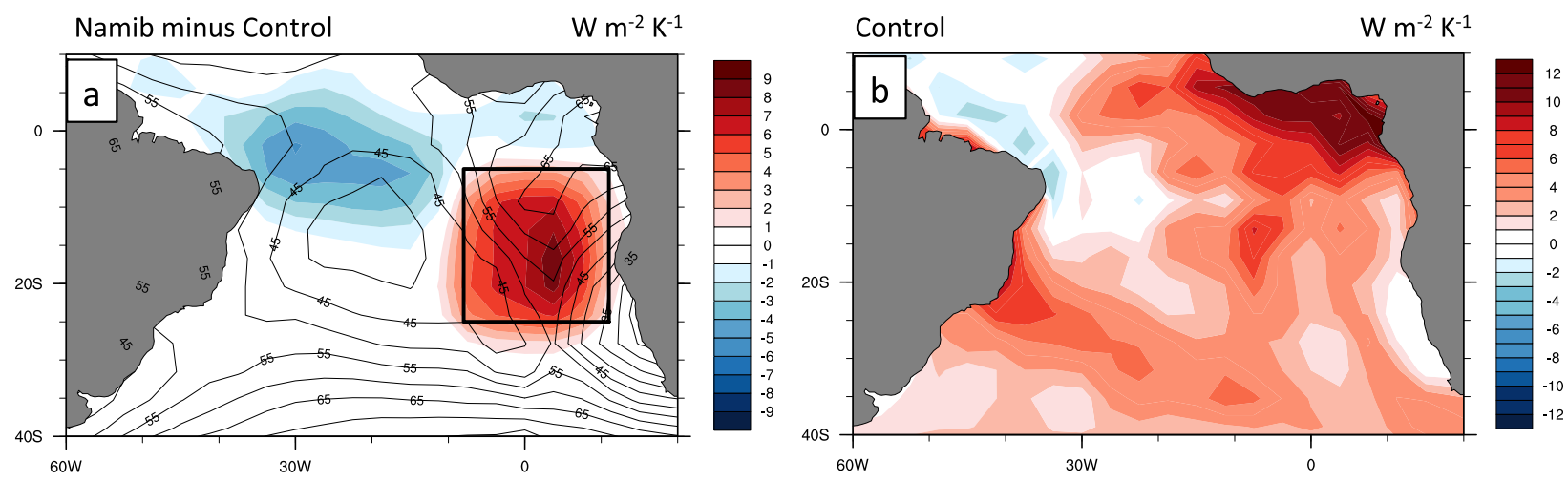

FIG. 4. (a) Difference in local cloud feedback between Namib and the control simulation. Cloud feedback is computed as regression of local CRE at the surface on SST (units of $\mathrm{W} \mathrm{m}^{-2} \mathrm{~K}^{-1}$ ). Contours represent mean cloud cover climatology in the control simulation. The black box represents the Namib region. (b) Cloud feedback in the control simulation.

the Namib region shows values of cloud feedback that are stronger and more similar to observations, while over the equator it shows smaller but still positive cloud feedback. Although there are still differences between the simulations and observations, especially along the equator, the simulation of cloud feedback in the Namib experiment is closer to observations and helps us interpret the role of cloud feedbacks in regulating SSTs. Moreover, since we only enhance cloud feedback, these experiments are helpful to separate the role of cloud feedbacks on the simulated internal climate variability from other processes.

The effect of increasing the strength of the positive cloud feedback over the Namibian region (Fig. 4a) is an overall increase in the variance of SST and SLP (Fig. 5), both locally, where the feedback is enhanced, and remotely in the equatorial regions. Figures $5 \mathrm{a}$ and $5 \mathrm{c}$ show the climatological-mean SST and SLP variance, respectively. Compared to the climatological mean, the Namib experiment displays enhanced variance of both SST and SLP as shown by the ratio of variance of SST and SLP in the Namib experiment to the control run in Figs. $5 \mathrm{~b}$ and $5 \mathrm{~d}$, respectively. In the control simulation, the variance of SLP (Fig. 5c) resembles observations (not shown) but is smaller than observations over the Namibian region, while the variance of SST (Fig. 5a) is smaller than observations (not shown) both over the Namibian region and the equatorial Atlantic because of the absence of ocean dynamics in the slab-ocean configuration (Clement et al. 2011). It is noteworthy that the increase in the strength of cloud feedback over the Namibian region alone can more than double equatorial variability and make the variance of SST and SLP more similar to what is observed. This happens despite the increased local cloud radiative damping of SST anomalies (Fig. 4a).
Another important effect of enhanced cloud feedback over the Namibian region is an increase in the persistence of SST anomalies as measured by the $e$-folding time scale, which is defined as the month at which the autocorrelation of local SST anomalies drops below a value equal to or smaller than $1 / e$ at each grid point. Figure 6 shows the $e$-folding time scale in the control simulation (Fig. 6a) and the difference in $e$-folding time scale between the Namib experiment and the control simulation (Fig. 6b). In the control simulation the largest $e$-folding time is found off the coasts of Namibia (Fig. 6a), while in the Namib experiment the largest increase occurs at about $5^{\circ} \mathrm{S}$ in the eastern part of the basin (Fig. 6b). Interestingly, the variance of SST and SLP and the $e$-folding time are all enhanced in nearequatorial regions far away from where cloud feedback is increased.

The remote influence of cloud feedbacks in the subtropics on equatorial SST indicates that regional cloud feedbacks are connected to large-scale atmospheric circulation and climate variability patterns. In particular, cloud fluctuations and their influence on local SST in the Namibian region are connected to equatorial climate variability. To understand this influence as a function of time scale, we compute power spectra of SST anomalies averaged over the Atl3 region in the control simulation (black) and Namib experiment (red) in Fig. 7. Black markers on the red curve (Namib experiment) indicate where the difference in variance from the control run is statistically significant at the $95 \%$ level of a Fisher's F test for variances. Figure 7 shows that positive cloud feedback over the Namibian stratocumulus deck significantly increases the variance of equatorial SST anomalies at interannual to decadal time scales.

To quantify the contribution of the imposed cloud feedbacks to modes of variability, we perform an EOF 

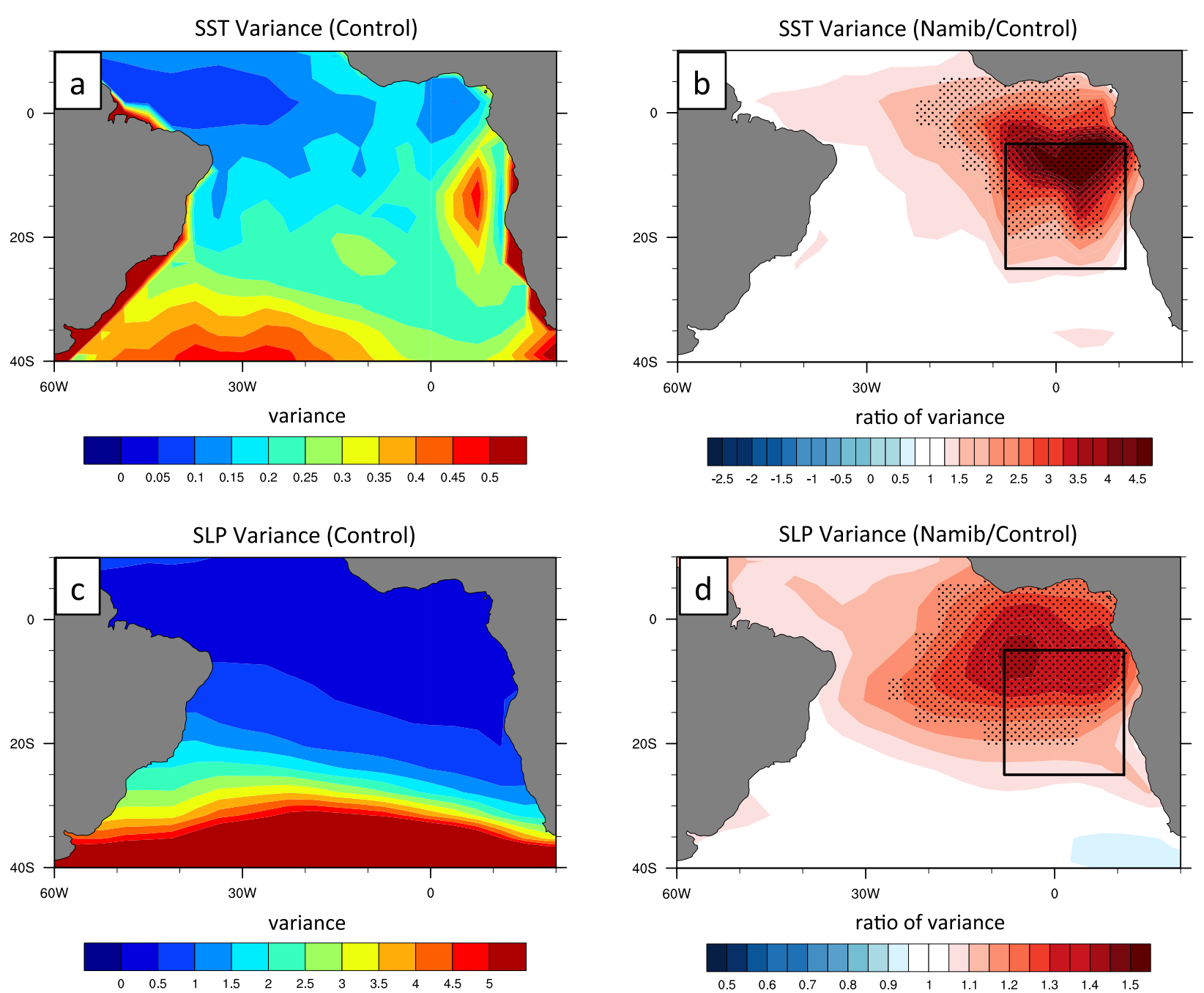

FIG. 5. (a) Variance of SST in the control simulation. (b) Ratio of variance of SST in the Namib experiment to the control simulation. (c) Variance of SLP in the control simulation. (d) Ratio of variance of SLP in the Namib experiment to the control simulation. Stippling indicates where the difference in variance between the Namib and the control simulations is significant at the $95 \%$ level of a Fisher's F test. The black box indicates the Namib region.

analysis on South Atlantic SST anomalies $\left(40^{\circ} \mathrm{S}-10^{\circ} \mathrm{N}\right.$, $50^{\circ} \mathrm{W}-20^{\circ} \mathrm{E}$ ) in the control and Namib simulations (not shown). The first EOF exhibits a mode of variability as the one seen from observations (Fig. 2) and explains $16.4 \%$ of the variance. This mode of variability is referred to as the South Atlantic dipole in the literature (e.g., Trzaska et al. 2007) and explains $\sim 20 \%$ of SST variance in observations (not shown). The first EOF in the Namib experiment also exhibits the same mode but explains a larger variance $(23.3 \%)$ at the equator because of the enhancement of Atlantic Niño variability (Fig. 5b).

These results collectively indicate that cloud feedbacks from the eastern subtropical Atlantic can play an important role in setting the time scale and amplitude of equatorial modes of variability especially at lowfrequency time scales. In the following sections, we will explore whether equatorial SSTs are influenced by other regions in the South Atlantic (section 3c); examine the mechanisms connecting the Namib region to the equator (section 3d); and provide a heat flux framework to interpret these mechanisms (section 3e).

\section{c. Role of cloud feedbacks over the other regions in the South Atlantic}

To test the possible role of other regions in the South Atlantic, we perform nine experiments in which we increase the strength of positive cloud feedback over the nine boxes shown in Fig. 1. We note that, while in the Namib region cloud liquid water is mostly present at 

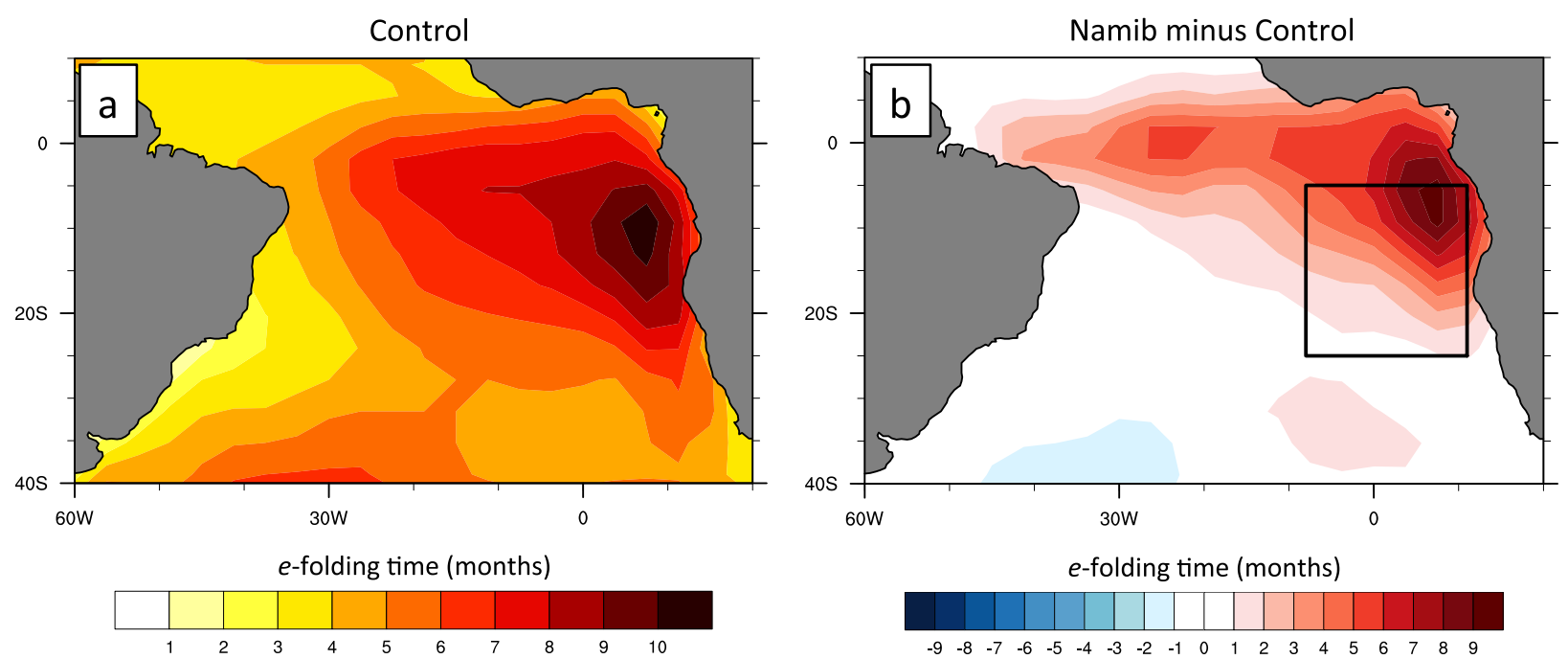

FIG. 6. (a) The $e$-folding time scale in the control simulation. (b) Difference in the $e$-folding time scale between the Namib and the control simulations. The black box indicates the Namib region.

lower levels in the atmosphere (below $700 \mathrm{hPa}$ ), in the other regions over the South Atlantic it can be present also at upper levels, especially where deep convection is more common: for instance, along the equator in the South Atlantic convergence zone. This means that in these nine experiments we are not enhancing only lowlevel cloud feedbacks. Moreover, differently from observations, cloud feedback over the deep-convective regions in the model has a net positive sign, like over the Namibia region (Fig. 4b). However, despite these differences from observations, these experiments will reveal the regions over the tropical South Atlantic where the positive feedback between cloud cover and SST can trigger a response over the equatorial Atlantic.

Figure 8 shows the difference in cloud feedback between the nine enhanced cloud feedback experiments and the control simulation. Cloud feedback is estimated as in Fig. 4 as the regression of local CRE at the surface on local SST. Although we enhance positive cloud feedback in the same manner in all regions, we see from Fig. 8 that regions where low clouds are more common over the eastern Atlantic (e.g., box 6 over the Namibian region) display a more enhanced positive cloud feedback. This is because the total cloud cover is larger where low-level clouds predominate.

The response to enhanced feedbacks, however, is not trivially proportional to the change in cloud feedback strength shown in Fig. 8. Figure 9 shows the ratio of SST variance in the nine cloud feedback experiments to the control simulation and there is not linear relationship between enhanced cloud feedback (Fig. 8) and SST variance (Fig. 9). This is even more evident in Fig. 10, which shows the difference in cloud feedback from Fig. 8 (green bars) versus the ratio of SST variance (orange bars) averaged over the nine boxes in each corresponding experiments (i.e., the bars for "box 1" represent the averages over the coordinates of box 1 in the box 1 experiment, etc.). For example, the variance of SST over box 2 increases as much as over box 1 , but the increase in cloud feedback over box 2 is much bigger than over box 1. This suggests that the change in SST variance must be explained by other terms in the surface heat budget.

In general, we find that the effects of enhanced cloud feedbacks in the western Atlantic (boxes 1, 4, and 7) and central equatorial Atlantic (box 2) are small, whereas the central South Atlantic (boxes 5 and 8) and the eastern Atlantic (boxes 3, 6, and 9) have more noticeable impacts (see Fig. 9). Box 6, which sits on the Namibian stratocumulus deck, has the largest impact on the variance of local and equatorial SST. The effectiveness of the cloud-SST coupling in this region highlights the importance of Namibian stratocumulus clouds in tropical Atlantic variability and is consistent with the results of the Namib experiment. Box 3, which is located at the eastern side of the equatorial Atlantic, also shows some influence on equatorial SST variance.

Cloud feedbacks over boxes 5 and 8 , which are located over the central part of the basin, enhance local SST variance, but they do not impact equatorial variability. Instead, cloud feedbacks over boxes 2 and 3, which are located over the equatorial Atlantic, increase SST variance not only along the equator but also over the central southern Atlantic (Fig. 9), in contrast with the effects of cloud feedback over box 8 , which shows no remote influence on SST variance along the equator. 


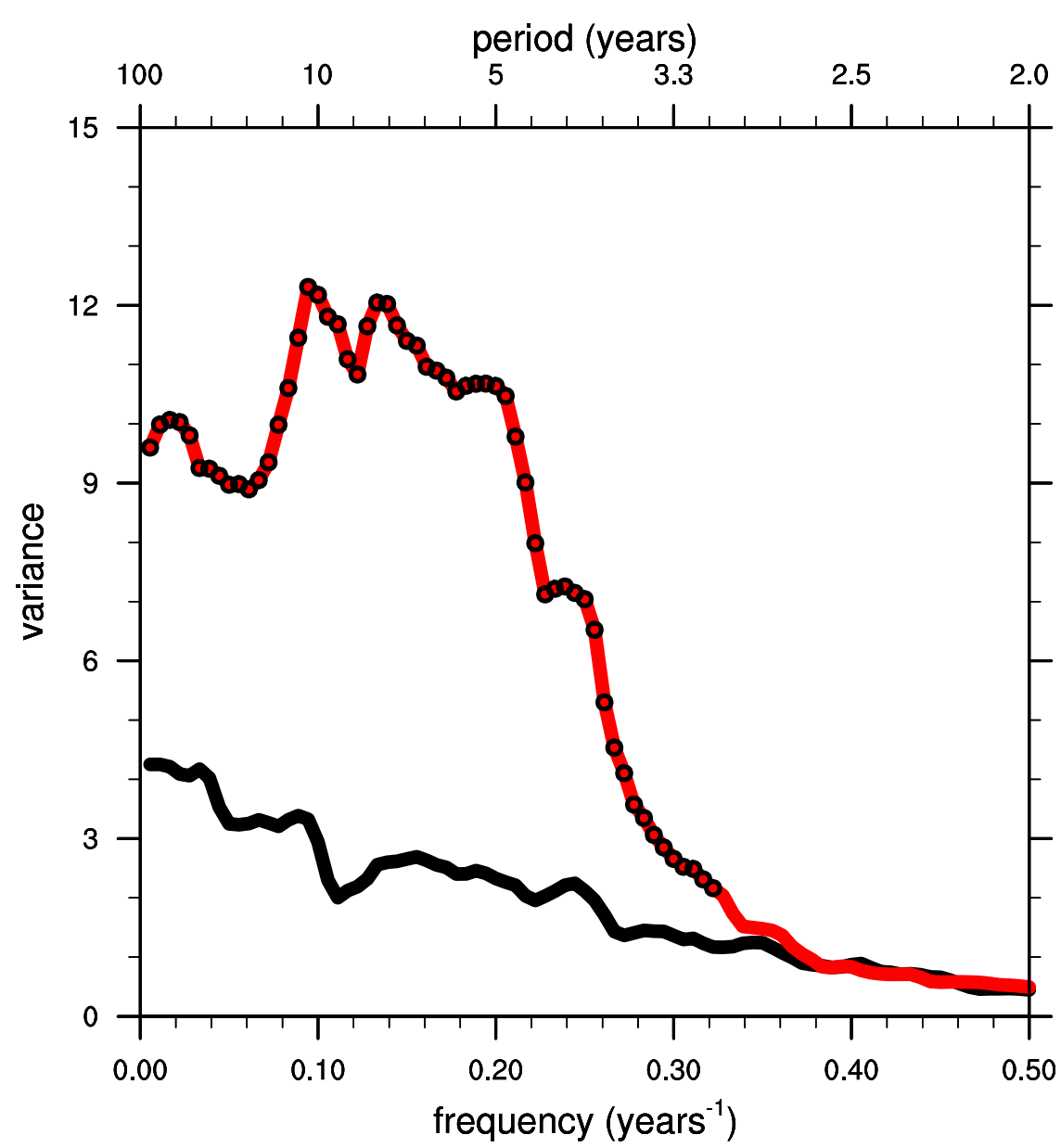

FIG. 7. Power spectra of SST averaged over the Atl 3 region $\left(5^{\circ} \mathrm{S}-5^{\circ} \mathrm{N}, 20^{\circ} \mathrm{W}-0^{\circ}\right)$ in the $\mathrm{Namib}$ experiment (red) and control simulation (black). A 24-month smoothing has been applied to the periodogram estimates. Black dots indicate where the variance of the Namib curve is significantly different from the variance of the control simulation at the $95 \%$ level of a Fisher's F test.

In regards to the effects of these regional cloud feedbacks on the persistence of SST anomalies, the difference in $e$-folding time scale between the nine experiments and the control simulation in Fig. 11 shows very little influence of cloud feedbacks from all regions, with the exception of box 6 (Namibian region) and possibly box 3 (eastern equatorial Atlantic). We note that positive cloud feedbacks over some regions on the western side of the Atlantic actually tend to reduce the persistence of SST anomalies along the eastern equatorial Atlantic (boxes 1, 2, and 7 in Fig. 10), but these effects are small.

The more decisive role of positive cloud feedbacks over the Namibian region (box 6) compared to the equatorial eastern Atlantic (box 3) is most clearly seen from power spectra of SST anomalies of the Atl3 index computed for the nine regional experiments (Fig. 12).
Compared to the control simulation (black), the only box that clearly enhances the variance of SST at interannual and longer time scales is box 6 (magenta). Since the difference in $e$-folding time scale shown in Fig. 11 indicates that box 3 over the eastern equatorial Atlantic also exerts an influence on the persistence of SST anomalies, we ran boxes 3 and 6 for an additional $50 \mathrm{yr}$ to ensure that the effects of cloud feedback over box 6 are not due to the length of the simulation. These longer simulations are represented by lines with dot markers in Fig. 12. The longer time series show no effects on Atl3 SST anomalies from box 3 (dotted orange line), while the effects from box 6 (dotted magenta line) become even more evident with a longer simulation, especially at low-frequency time scales. For reference, we plot the power spectra for the Namib experiment for $80 \mathrm{yr}$ of simulation (solid gray line) and the full 


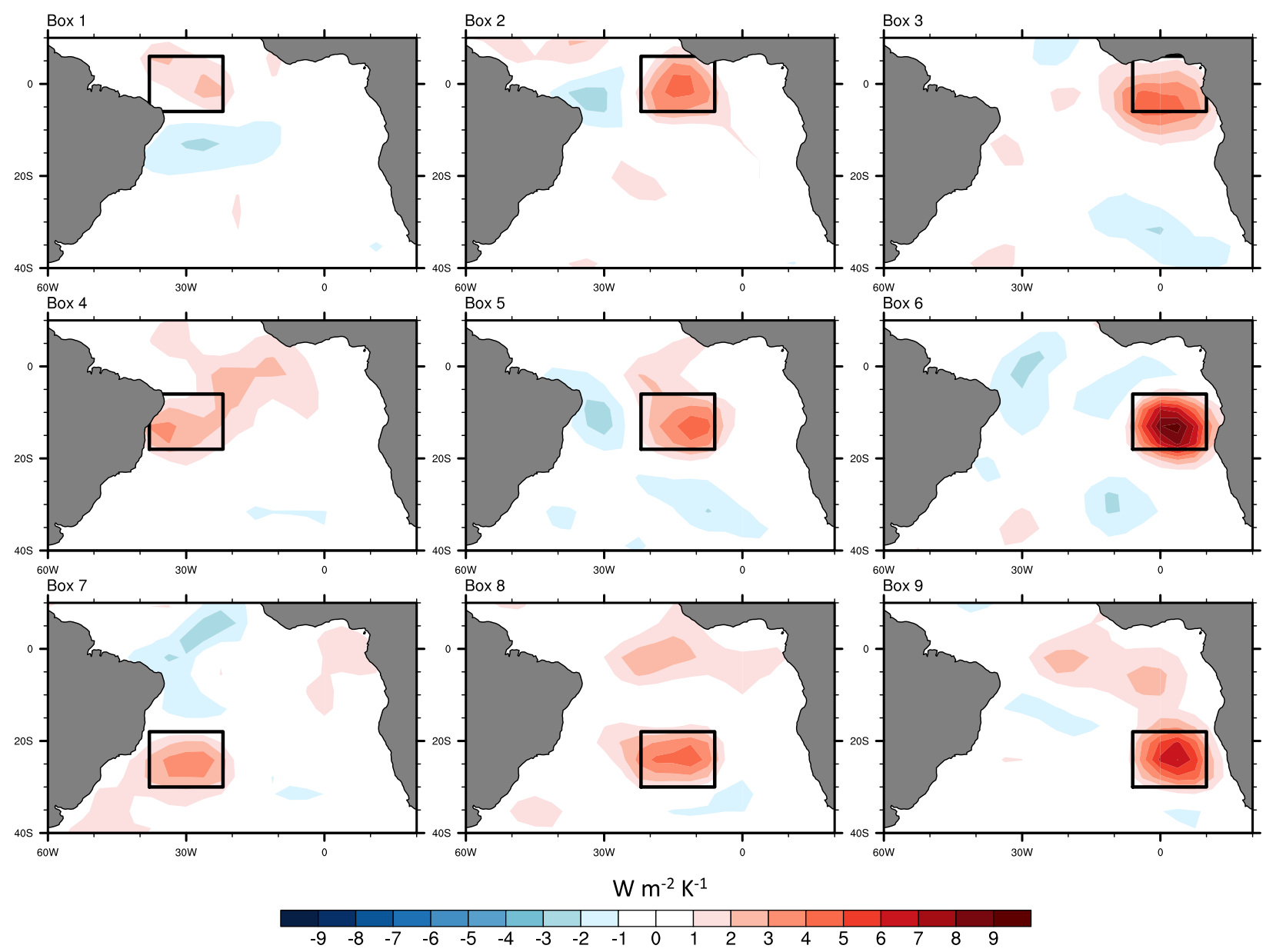

FIG. 8. Difference in cloud feedback between enhanced cloud feedback experiments and the control simulation. Cloud feedback is estimated as regression of local CRE at the surface on SST, with units of $\mathrm{W} \mathrm{m}^{-2} \mathrm{~K}^{-1}$ (as in Fig. 4). The black-boxed regions in each plot indicate where positive cloud feedback is enhanced.

simulation (180yr; dotted gray line). The Namib experiment increases the variance of equatorial SST anomalies by even more than box 6 . Consistently with the values of $e$-folding time scale in Fig. 11, the boxes over the western Atlantic reduce the variance of the Atl3 index.

To verify that box 6 has not the largest impact on SST variance just because enhanced cloud feedback is larger than over the other boxes (Figs. 8 and 10), an additional experiment has been performed in which we make cloud feedback over box 6 less sensitive to SST (referred to as box $6 \mathrm{~b}$ ). In this experiment, we change the relationship between cloud liquid water and SST anomaly in Eq. (1) to

$$
y=1-0.7 \arctan (0.7 \mathrm{SST}) 2 / \pi \text {. }
$$

Although the overall increase in variance is less than that shown by box 6 (see corresponding bars in Fig. 10), box $6 \mathrm{~b}$ still exhibits a large response at the equator, especially at lower frequencies, which is different from all the other boxes (see the box $6 \mathrm{~b}$ curve in the power spectra of Fig. 12).

In separate experiments, we enhanced the strength of cloud feedback according to Eq. (1) in the entire North Atlantic basin and over the North Atlantic subtropical stratocumulus region (Canaries). These experiments show that enhanced cloud feedbacks over the North Atlantic influence SST variability in the North Atlantic basin but have no effects on equatorial Atlantic variability.

In conclusion, both an analysis of observational data and our modeling results suggest that the Namibian region plays a fundamental role on local and equatorial SST variability. Because we also verify that the central role of the Namibian region on equatorial SSTs is not trivially related to (i) the fact that the enhancement of cloud feedback is most effective over the Namibian 

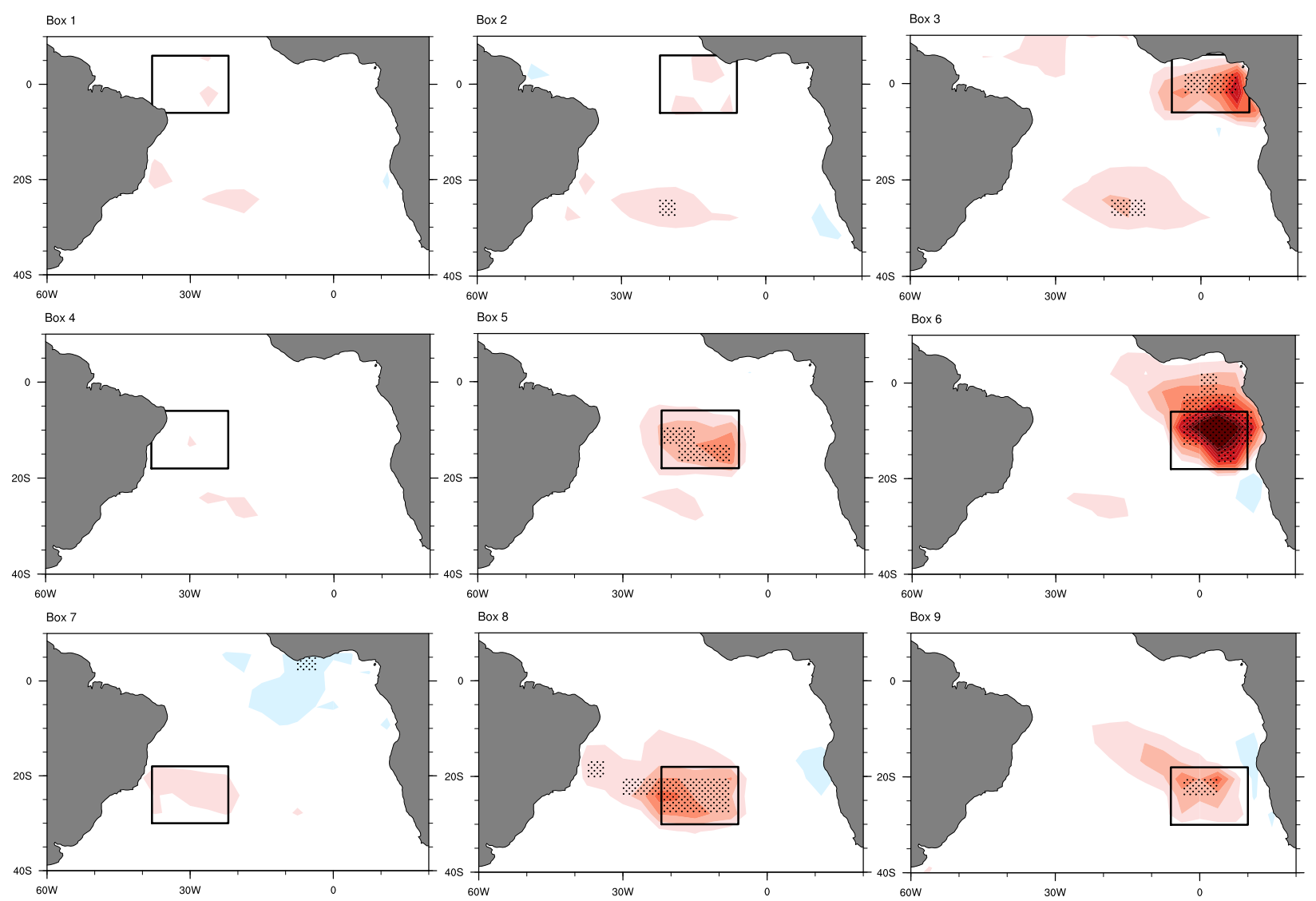

Box 9

ratio of variance

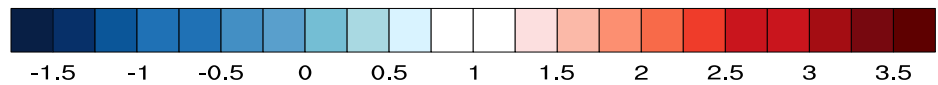

FIG. 9. Ratio of variance of SST in the nine enhanced cloud feedback experiments to the control simulation. Stippling indicates where the difference in variance between the enhanced cloud feedback experiments and the control simulation is significant at the $85 \%$ level of a Fisher's F test.

region (Fig. 8) or (ii) the length of the simulation (Fig. 12), we now investigate in further detail the mechanisms of Atlantic Niño variability in our slabocean simulations and the role of the Namibian region.

\section{d. The relationship between the Namibian region and equatorial Atlantic variability}

To understand why low-level cloud feedbacks over the Namibian region have a remote influence along the equator, we compare the mean state of SST (shaded), SLP (contours), and winds (vectors) in the control run (Fig. 13) with lagged composites of these same variables during warm events of the Atl3 SST index in the Namib experiment (Fig. 14). Warm events are chosen as the months at which SST anomalies averaged over the Atl3 region exceed one standard deviation of the Atl3 index time series. We show the Namib experiment because anomalies are larger but results are consistent if we use the control simulation. We obtain qualitatively similar results if we increase the threshold for warm events from 1.0 to 1.5 standard deviations or we look at cold instead of warm events.

In the mean state, the South Atlantic climate (Fig. 13) is characterized by east-west and north-south gradients of SST with relatively colder SSTs where Namibian stratocumulus clouds are located. Mean surface winds are southeasterly over the Namibian region and easterly along the equator, and there is a counterclockwise circulation at $30^{\circ} \mathrm{S}$ associated with the subtropical high.

Lagged composites of Atl3 index warm events (Fig. 14) show that anomalously warm SSTs develop over the southeast Atlantic at approximately $20^{\circ} \mathrm{S}$ at a lag of -18 months from the peak of the warm events along with a weakening of the atmospheric circulation in the central part of the basin (Fig. 14a). SSTs remain anomalously warm over the southeast Atlantic throughout 


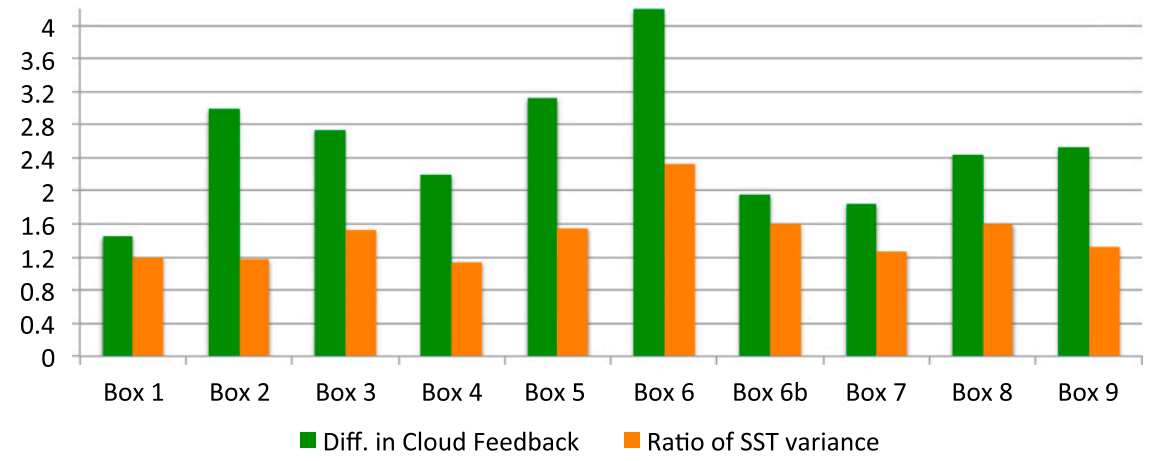

FIG. 10. Values of difference in cloud feedback from Fig. 8 (green) and ratios of SST variance from Fig. 9 (orange) averaged over the nine boxes in each corresponding experiment. Units are $\mathrm{W} \mathrm{m}^{-2} \mathrm{~K}^{-1}$ for the differences in cloud feedback, whereas the ratios of SST variance are unitless.

the development of the event, while weaker trade winds favor the progressive warming of SSTs over the northeastern part of the basin through the wind-evaporationSST (WES) feedback (Zhou and Carton 1998), until the Atl3 region (black box) reaches its warm peak. The WES feedback can be briefly explained as follows: A local warm (cool) SST anomaly favors weakening (strengthening) of winds, which affects winds and latent heat fluxes downwind the anomaly, thereby promoting a downwind expansion of the anomaly. Signals propagate via the WES feedback both zonally and meridionally, depending on the mean climate (Wang 2010).
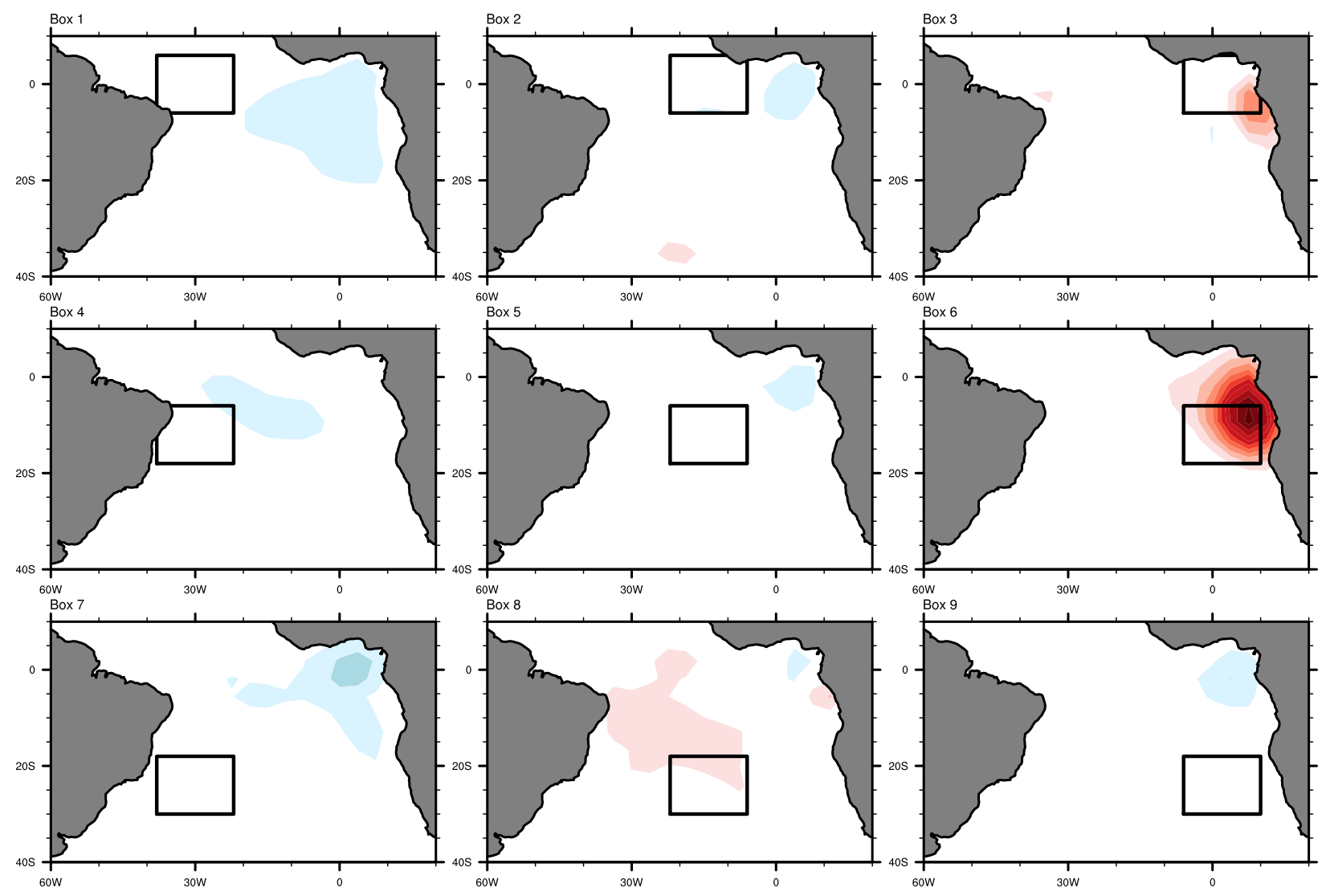

e-folding time (months)

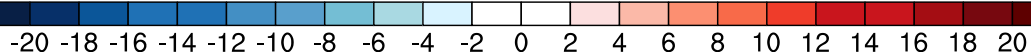

FIG. 11. Difference in $e$-folding time scale between the nine enhanced cloud feedback experiments and the control simulation. 


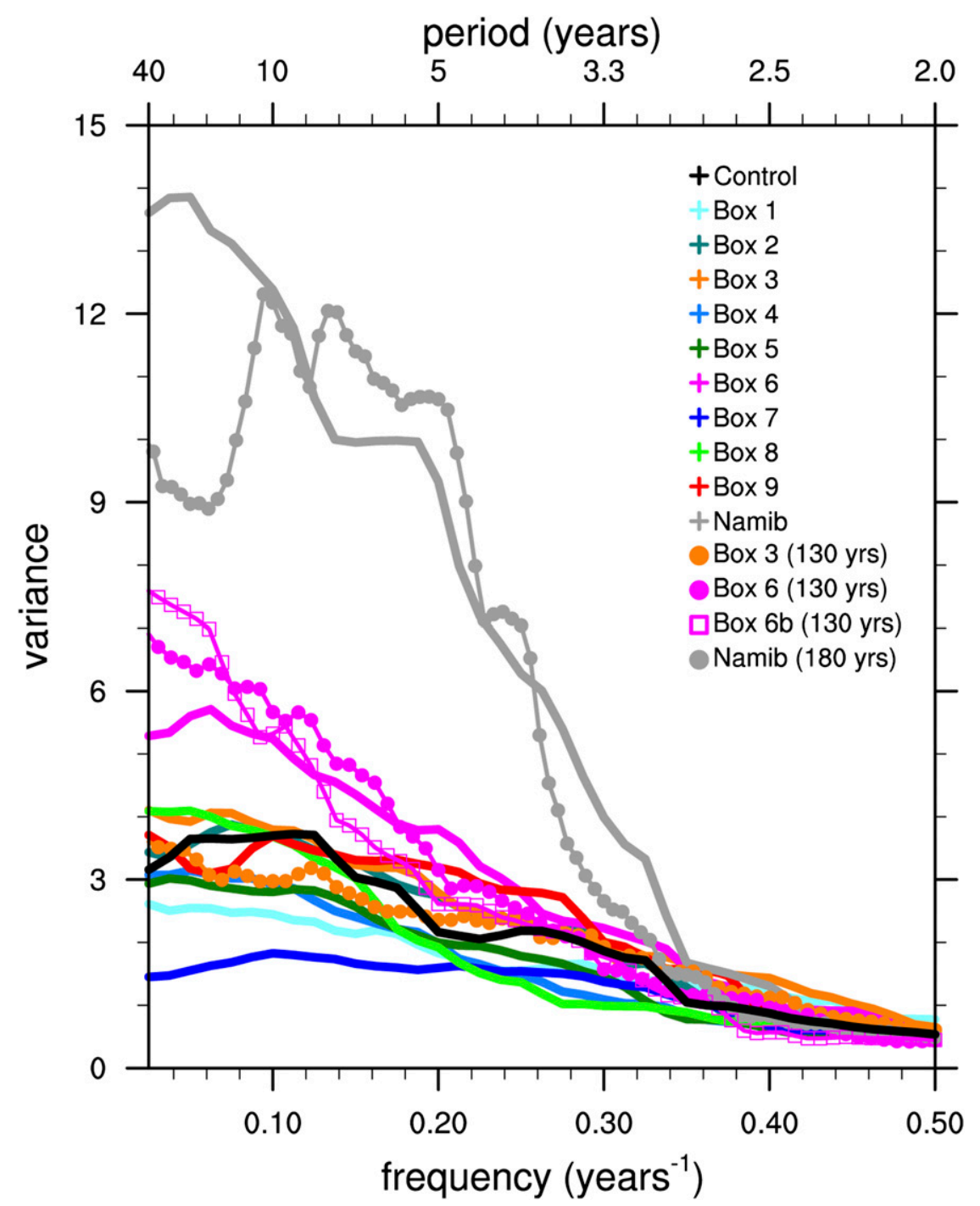

FIG. 12. Power spectra of SST averaged over the Atl 3 region $\left(5^{\circ} \mathrm{S}-5^{\circ} \mathrm{N}, 20^{\circ} \mathrm{W}-0^{\circ}\right)$ in the control simulation (black) and enhanced cloud feedback experiments (colors; see legend). A 24-month smoothing has been applied to the periodogram estimates. The power spectra are computed on time series of $80 \mathrm{yr}$ with the exception of the lines with markers (see legend).

Differently from the other eight regions, the Namib region has mean southeasterly trades; along with its location upstream of the Atl3 region, this makes the Namib region uniquely suited for influencing eastern equatorial Atlantic (cf. Klein et al. 1995).

The southwestern part of the basin, characterized by an opposite sign, cold SST anomaly, is driven by different but complementary mechanisms. If we compare this region with the mean climate in Fig. 13, we see a strengthening rather than a weakening of the surface winds. The strengthening of the surface winds through latent heat fluxes and the advection of cold air from the southern midlatitudes promote colder SSTs in the southwest part of the basin.
The analysis of composites of the control simulation shows qualitatively similar results to those shown in Fig. 14 for the Namib experiment. The differences between the two simulations are in the persistence of the events (cf. Fig. 6), with the control simulation showing the first SST anomalies over the southeast Atlantic at lag -12 instead of lag -18 , and the magnitude of the events, with the control simulation exhibiting weaker SST anomalies.

It is reassuring that the mechanisms of the simulated Atlantic Niño in the slab-ocean simulations appear similar to observations. The composites of SST and atmospheric circulation on the Atl3 index at lag 0 (Fig. 14d) resemble the observed anomalies associated with Atlantic Niño (Fig. 2), although ocean dynamics 


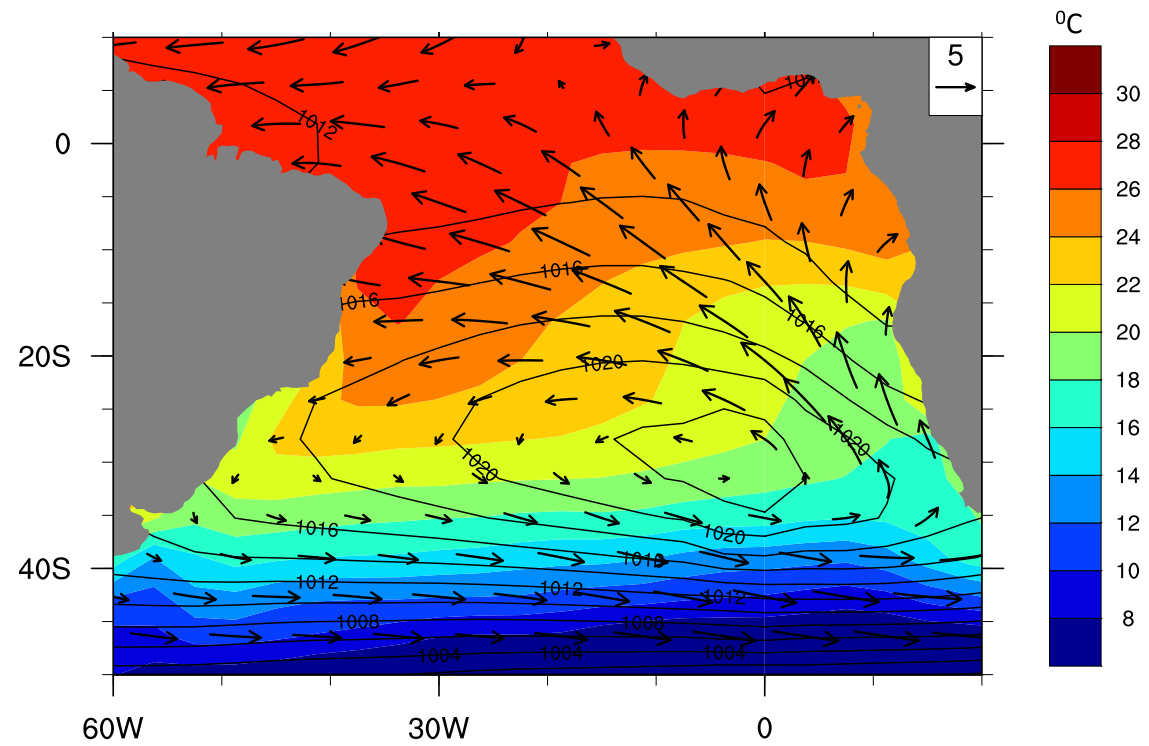

FIG. 13. Mean climatology in the control simulation: SST (shaded; in ${ }^{\circ} \mathrm{C}$ ), SLP (contours; in hPa), and surface winds (vectors; in $\mathrm{m} \mathrm{s}^{-1}$ ).

are absent in our simulations (cf. Trzaska et al. 2007). Moreover, composites of the same fields in observations give similar results as in Fig. 14 (not shown). Therefore, understanding the dynamics of slab-ocean Atlantic Niño and the role of cloud feedbacks is relevant to understand the processes driving Atlantic Niño and its persistence in the real world (cf. Dommenget et al. 2014).

\section{e. Analysis of surface flux damping rates}

The variability of SST anomalies associated with Atlantic Niño can be explored using the Frankignoul and Hasselmann (1977) framework, according to which the persistence of SST anomalies is tied to the damping rate $(\lambda)$ of SST,

$$
\rho C_{p} H \frac{d T}{d t}=-\lambda T+N,
$$

where $T$ is the temperature of the mixed layer (i.e., SST), $H$ is the depth of the mixed layer, $\rho$ is the density of seawater, and $C_{p}$ is the specific heat capacity of seawater at constant pressure. The term $N$ is interpreted as stochastic noise from atmospheric dynamics that is integrated by the oceanic mixed layer. According to Eq. (4), the persistence of SST is largest where the damping rate $\lambda$ is weakest and the depth of the mixed layer $H$ is greatest. In our experiments, $H$ does not change; therefore, it does not influence the persistence of SST.

The damping rates can be linearly decomposed into contributions from each surface flux terms. Positive damping rates reduce the persistence of SST anomalies, while negative damping rates increase their persistence [cf. Eq. (4)]. We calculate the damping rates as in Park et al. (2005),

$$
\lambda_{i}=\frac{\operatorname{cov}\left[Q_{i}(-L), \operatorname{SST}(0)\right]}{\operatorname{cov}[\operatorname{SST}(-L), \operatorname{SST}(0)]},
$$

where $\lambda_{i}$ is the damping rate of each of the four surface fluxes $Q_{i}$ (clear-sky radiation, CRE, latent heat, and sensible heat) and $-L$ indicates negative lags. In the equation, cov stands for covariance. Each $\lambda_{i}$ is computed as the average of the first three negative lags $(-1,-2$, and -3 months).

Figure $15 \mathrm{~b}$ shows that the sum of damping rates of the four surface fluxes is positive: that is, the fluxes tend to restore SST anomalies to their climatological mean. Of the four surface fluxes, the largest contribution to positive values comes from the latent heat flux (contours in Fig. 15b), while the damping rate due to CRE is negative because cloud feedbacks tend to increase the persistence of SST anomalies over the eastern part of the basin (not shown). The damping rates associated with sensible heat and clear-sky radiation are one order of magnitude smaller.

The sign of the surface flux damping rates in the model is consistent with the observational estimates of Park et al. (2005), while the meridional structure of the damping rate is similar to the one estimated by Evan et al. (2013) (their Fig. 5). The spatial pattern of the damping rate in Fig. 15b is also consistent with the equatorial expansion of SST anomalies seen from the lagged composites (Fig. 14). In fact, damping rates are weakest along the eastern part of the basin; hence, with large-scale weakening of the trade 

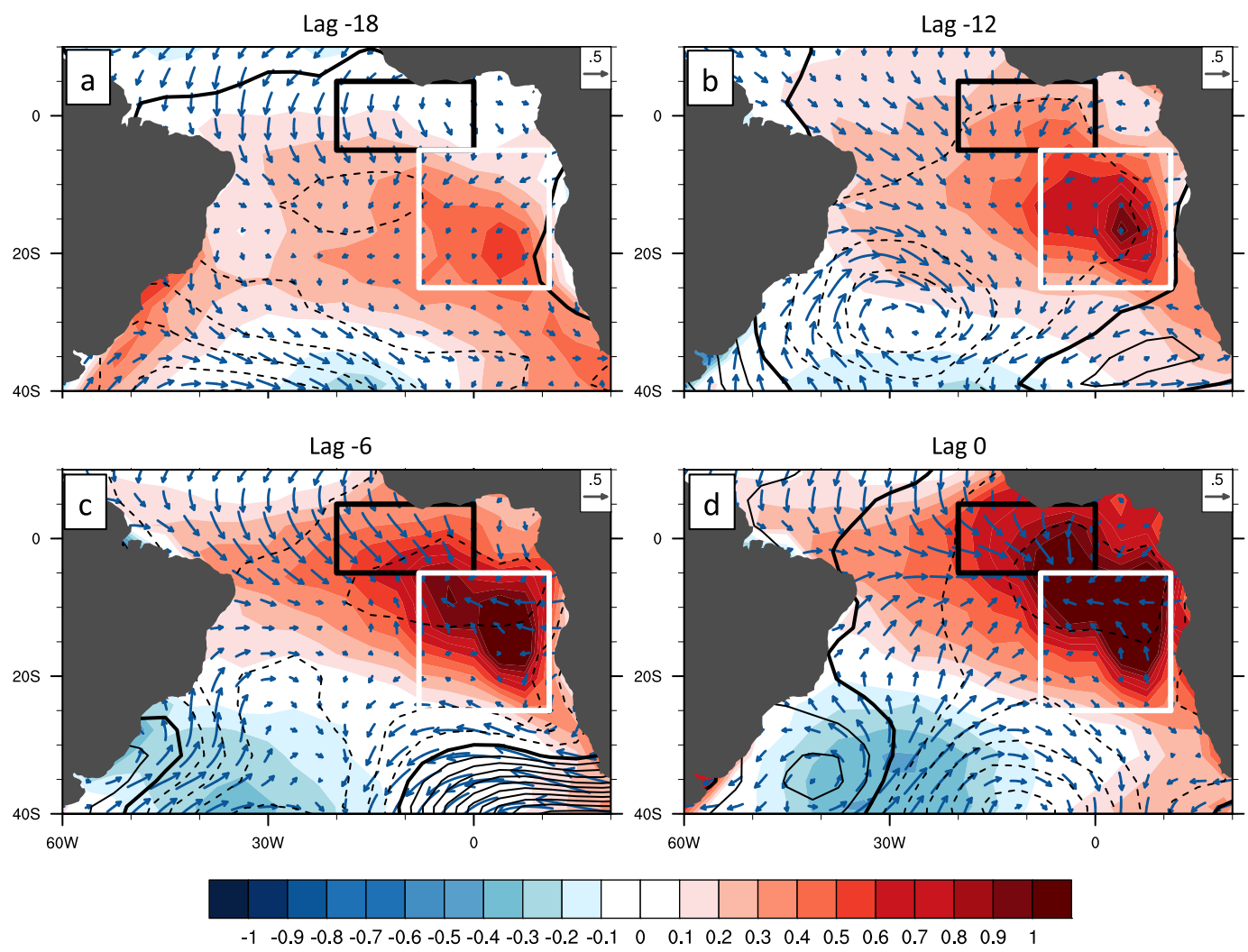

FIG. 14. Lagged composites of warm Atl3 index events in the Namib experiment: SST (shaded; units of ${ }^{\circ} \mathrm{C}$ ), SLP (contours; units of $\mathrm{hPa}$, ranging from -2 to $2 \mathrm{hPa}$ with intervals of $0.2 \mathrm{hPa}$ ), and surface winds (vectors; units of $\mathrm{m} \mathrm{s}^{-1}$ ). Lags are (a) -18 , (b) -12 , (c) -6 , and (d) 0 months from the peak of the event. The white box highlights the Namib region, whereas the black box highlights the Atl3 region.

winds, SST anomalies are the same sign and maximum in amplitude over the Namibian and eastern equatorial regions. Instead, the stronger damping rates over boxes 1,2, 4, and 7 explain why the variance of SST (Fig. 9) does not increase as a function of cloud feedbacks as much as it does in the eastern part of the basin.

It is important to note that the SST anomalies associated with Atlantic Niño develop at a lag of -18 months, where the variance of SST is largest (Fig. 14), which occurs over the Namibian region (Fig. 15d) and not at the equator, even though we composite by At13 SST anomalies. Also, in the control simulation the peak of the composites (lag 0 ) occurs where the variance is largest in the control simulation and not in the Atl3 region. In the slab-ocean experiments, the variance of SST (Fig. 15d) can be explained to the first order as the variance of total surface fluxes (Fig. 15a) scaled by the sum of the damping rates of these fluxes (Fig. 15b). In fact, Fig. 15c shows the variance of total fluxes divided by their total damping rate, which exhibits a spatial pattern that largely resembles the variance of SST (Fig. 15d). When we enhance cloud feedback over box 6 (black box) or the Namibian region (red box), we introduce a positive feedback that increases the variance of total surface flux and decreases its damping rate (not shown) and therefore increases the variance of SST. Box 6 has a smaller effect than the Namib experiment on equatorial SST spectra (Fig. 12) because the Namib experiment encompasses a bigger region than box 6 (see boxes in Fig. 15d) where SST variance is large and damping rate is small.

In summary, SST anomalies prior to warming in Atlantic Niños develop where the variance of SST is largest and the damping rate of SST is weakest: that is, over the Namibian region. This region has mean winds that are favorable for propagation into the eastern equatorial Atlantic. Thus, both positive cloud feedback and its geographical position explain why the Namibian subtropical stratocumulus area is the most important region in affecting equatorial climate variability and the slab-ocean Atlantic Niño.

\section{Summary}

Previous studies have shown the importance of stratocumulus clouds over the Namibian region in enhancing 

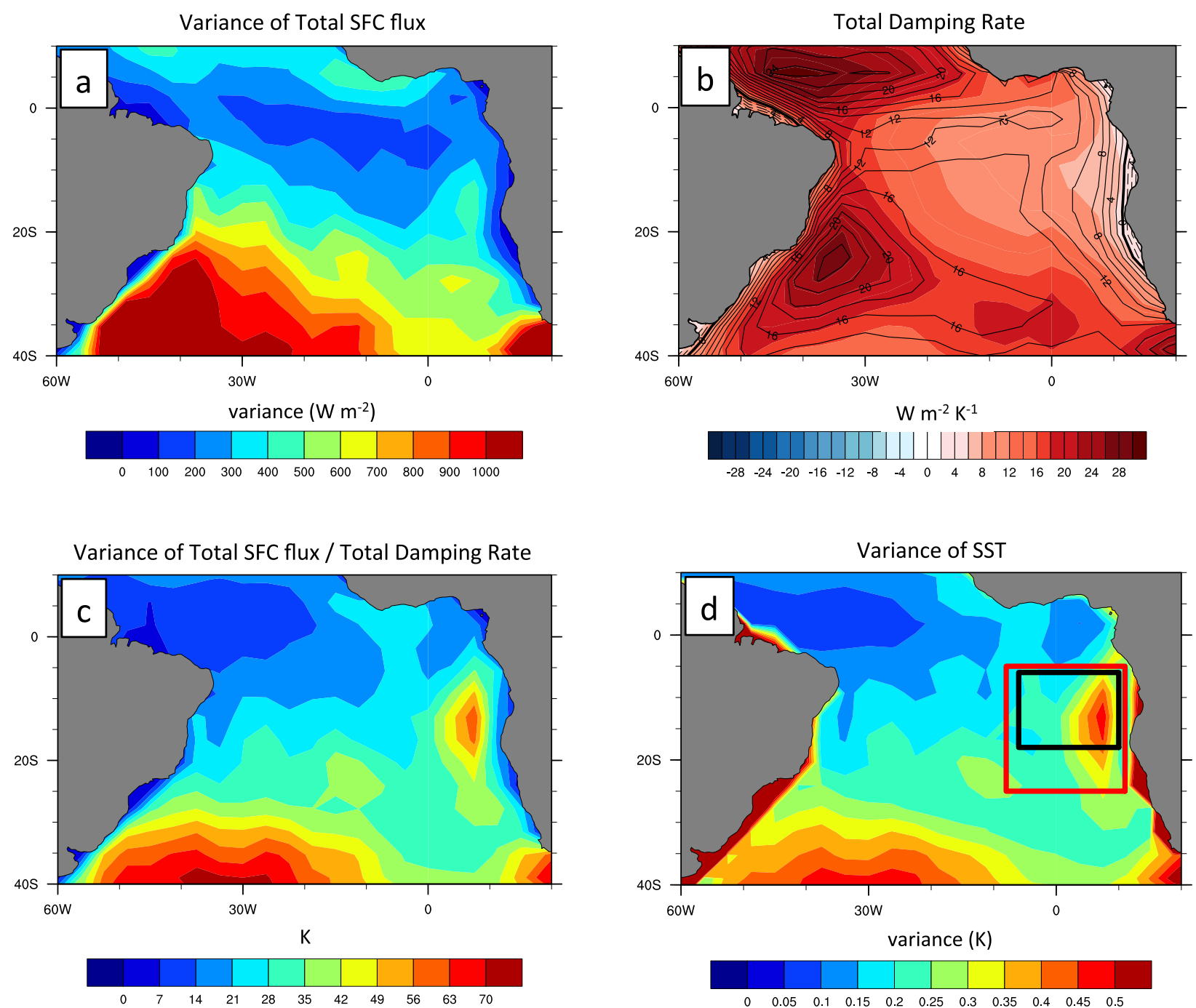

FIG. 15. (a) Variance of the sum of the net surface fluxes (longwave + shortwave + latent + sensible). (b) Damping rate of net surface fluxes computed as in Park et al. (2005). (c) Variance of net surface fluxes divided by their damping rate. (d) Variance of SST in the control simulation (as in Fig. 5a). The box of the Namib experiment (red) and the box of the box 6 experiment (black) are superimposed.

meridional modes of variability both in observations and theoretical models (e.g., Tanimoto and Xie 2002; Evan et al. 2013). For example, Evan et al. (2013) showed that, in the absence of cloud feedbacks over the stratocumulus regions, the magnitude of the WES feedback associated with meridionally propagating modes would not be sufficient to overcome the damping rates of SST anomalies. Klein et al. (1995) also showed in observations that stratocumulus clouds respond to upstream SST anomalies enhancing the WES feedback and the propagation of SST anomalies. Here, we build on these previous studies by examining the role of cloud feedbacks in a full AGCM coupled to a slab ocean and focusing on the role of cloud feedbacks on equatorial Atlantic variability.
We examine observations of cloud radiative effect and show that Atlantic Niño SST anomalies covary with positive cloud feedback over the Namibian stratocumulus region. Changes in cloud cover seen in observations over this region can influence the persistence of SST anomalies (e.g., Park et al. 2005), but from observations alone it is not possible to distinguish the role of regional cloud feedbacks on large-scale climate variability from other processes.

To address this issue, we perform sensitivity experiments using the atmospheric component (ECHAM6) of an Earth system model coupled to a slab ocean, in which we artificially increase the strength of positive cloud feedback over selected regions using the experimental design of Bellomo et al. (2014a). We show that low-level 
cloud feedback over the Namibian stratocumulus region influences the variance and persistence of largescale SST variability. In particular, low-level cloud feedback over the Namibian region enhances the simulated Atlantic Niño in the model. Together, model and observations suggest that cloud feedbacks can modify the characteristics and persistence of Atlantic Niño events.

We perform additional experiments to investigate the influence of cloud feedback in nine regions spanning the tropical South Atlantic $\left(5^{\circ} \mathrm{N}-30^{\circ} \mathrm{S}, 40^{\circ} \mathrm{W}-10^{\circ} \mathrm{E}\right)$. The purpose of these experiments is to determine whether other regions influence local or remote SST variability. We find that regions over the central and eastern South Atlantic south of $20^{\circ} \mathrm{S}$ increase only local SST variability; regions over the eastern South Atlantic north of $20^{\circ} \mathrm{S}$ increase both local and equatorial SST variability; and regions over the western South Atlantic do not influence local SST variability but they reduce equatorial SST variability, although their effects are small compared to the eastern regions. Of all the regions, the Namibian stratocumulus region has the strongest influence on the variance and persistence of equatorial Atlantic SSTs at interannual and longer time scales.

We investigate the mechanisms associated with the development of Atlantic Niño events using composites and regression analysis. We find that SST anomalies originating over the Namibian region are amplified by positive cloud feedbacks. These anomalies eventually favor anomalies of the same sign over the equatorial eastern Atlantic because they influence the strength of surface winds and associated latent heat fluxes through the WES feedback. The Namibian region has the largest impact of all the South Atlantic regions on the persistence of equatorial SST anomalies because it is located where Atlantic Niño events develop: that is, where the variance of SST is largest and the damping rate of SST is weakest.

Our approach is helpful to evaluate the effects of regional cloud-SST feedbacks on large-scale modes of variability. However, we note that the variability of cloud cover and its effects on SSTs is certainly influenced by other processes, including inversion strength, subsidence rate, radiative cooling above the boundary layer, and moisture above the inversion (e.g., Wood 2012), which we have not examined here. Moreover, in our experiments we keep the mixed layer depth fixed at $50 \mathrm{~m}$. The effects of including a seasonal mixed layer depth should be tested with a different experimental design; however, since we are interested in annual-mean climate fluctuations, a fixed mixed layer depth is justified. Terray (2011) argues that a shallower mixed layer during summer can lead to larger changes in SST, which may provide a rectified annual-mean change and could even amplify the effects of cloud feedbacks.

We also have not addressed the role of ocean dynamics here since our results are based on observations and experiments with an AGCM coupled to a slab ocean. Power spectra of Atl3 index in CMIP3 models coupled to slab-ocean and full-ocean models reveal that ocean dynamics enhance interannual variability with negligible effects at longer time scales (not shown), consistent with the results of Clement et al. (2011) for Pacific El Niño variability. Zhang et al. (2010) suggest that cloud feedbacks amplify the large-scale effects induced by changes in the Atlantic meridional overturning circulation (AMOC). Hence, the interaction of cloud feedbacks with ocean dynamics remains an interesting yet unresolved question.

Although we did not focus in this study on predictive skill, we note that predictability increases if a time series of SSTs is strongly autocorrelated (i.e., to predict the SST of next month, we assume that it will be the same as the present month scaled by the autocorrelation function of SST). Because increasing the strength of positive cloud feedback results in a more autocorrelated SST time series (as measured by the $e$-folding time), we expect that improving the simulation of cloud processes and the coupling between clouds, SST, and circulations (Evan et al. 2013; Stevens and Bony 2013) would lead to improved predictability of internal climate variability.

Acknowledgments. We thank Paquita Zuidema and Nathan Laxague for helpful comments and Amato Evan and two anonymous reviewers for insightful revisions. This work is supported by the Office of Science, U.S. DOE (Grant DESC0004897), NSF Climate and LargeScale Dynamics Program (Grant AGS0946225), NOAA Climate Program Office (Grant NA10OAR4310204), the Rosenstiel Alumni Fellowship (2012), and the Federal Ministry for Education and Research in Germany (BMBF) through the research program "MiKlip" (FKZ:01LP1158A).

\section{REFERENCES}

Barreiro, M., A. Giannini, P. Chang, and R. Saravannan, 2004: On the role of the South Atlantic atmospheric circulation in tropical Atlantic variability. Earth's Climate: The OceanAtmosphere Interaction, Geophys. Monogr., Vol. 147, Amer. Geophys. Union, 143-156.

Bellomo, K., A. C. Clement, T. Mauritsen, G. Rädel, and B. Stevens, 2014a: Simulating the role of subtropical stratocumulus clouds in driving Pacific climate variability. J. Climate, 27, 5119-5131, doi:10.1175/JCLI-D-13-00548.1.

,,-- J. R. Norris, and B. J. Soden, 2014b: Observational and model estimates of cloud amount feedback over the Indian and Pacific Oceans. J. Climate, 27, 925-940, doi:10.1175/ JCLI-D-13-00165.1. 
Biasutti, M., D. S. Battisti, and E. S. Sarachik, 2003: The annual cycle over the tropical Atlantic, South America, and Africa. J. Climate, 16, 2491-2508, doi:10.1175/1520-0442(2003)016<2491: TACOTT $>2.0 . \mathrm{CO} ; 2$.

Boyer, D. C., C. H. Kirchner, M. K. McAllister, A. Staby, and B. I. Staalesen, 2001: The orange roughy fishery of Namibia: Lessons to be learned about managing a developing fishery. S. Afr. J. Mar. Sci., 23, 205-221, doi:10.2989/025776101784528755.

Brundrit, G. B., 1995: Trends of southern African sea level: Statistical analysis and interpretation. S. Afr. J. Mar. Sci., 16, 9-17, doi:10.2989/025776195784156449.

Carton, J. A., X. Cao, B. S. Giese, and A. M. da Silva, 1996: Decadal and interannual SST variability in the tropical Atlantic Ocean. J. Phys. Oceanogr., 26, 1165-1175, doi:10.1175/ 1520-0485(1996)026<1165:DAISVI >2.0.CO;2.

Chang, P., L. Ji, and H. Li, 1997: A decadal climate variation in the tropical Atlantic Ocean from thermodynamic air-sea interactions. Nature, 385, 516-518, doi:10.1038/385516a0.

Chaves, R. R., and P. Nobre, 2004: Interactions between sea surface temperature over the South Atlantic Ocean and the South Atlantic convergence zone. Geophys. Res. Lett., 31, L03204, doi:10.1029/2003GL018647.

Chiang, J. C. H., and D. J. Vimont, 2004: Analogous Pacific and Atlantic meridional modes of tropical atmosphere-ocean variability. J. Climate, 17, 4143-4158, doi:10.1175/JCLI4953.1.

Clement, A. C., R. Burgman, and J. Norris, 2009: Model and observational evidence for positive low-level cloud feedback Science, 325, 460-464, doi:10.1126/science.1171255.

— , P. DiNezio, and C. Deser, 2011: Rethinking the ocean's role in the Southern Oscillation. J. Climate, 24, 4056-4072, doi:10.1175/2011JCLI3973.1.

Delecluse, P., J. Servain, C. Levy, K. Arpe, and L. Bengtsson, 1994: On the connection between the 1984 Atlantic warm event and the 1982-83 ENSO. Tellus, 46A, 448-464, doi:10.1034/ j.1600-0870.1994.t01-1-00009.x.

Dommenget, D., and M. Latif, 2000: Interannual to decadal variability in the tropical Atlantic. J. Climate, 13, 777-792, doi:10.1175/1520-0442(2000)013<0777:ITDVIT>2.0.CO;2.

_ S. Haase, T. Bayr, and C. Frauen, 2014: Analysis of the slabocean El Niño atmospheric feedbacks in observed and simulated ENSO dynamics. Climate Dyn., 42, 3187-3205, doi:10.1007/ s00382-014-2057-0.

Eastman, R., S. G. Warren, and C. J. Hahn, 2011: Variations in cloud cover and cloud types over the ocean from surface observations, 1954-2008. J. Climate, 24, 5914-5934, doi:10.1175/ 2011JCLI3972.1.

Enfield, D. B., A. M. Mestas-Nunez, D. A. Mayer, and L. CidSerrano, 1999: How ubiquitous is the dipole relationship in tropical Atlantic sea surface temperatures? J. Geophys. Res., 104, 7841-7848, doi:10.1029/1998JC900109.

Evan, A. T., R. J. Allen, D. J. Vimont, and R. Bennartz, 2013: The modification of sea surface temperature anomaly linear damping time scales by stratocumulus clouds. J. Climate, 26, 3619-3630, doi:10.1175/JCLI-D-12-00370.1.

Florenchie, P., J. R. E. Lutjeharms, C. J. C. Reason, S. Masson, and M. Rouault, 2003: The source of Benguela Niños in the South Atlantic Ocean. Geophys. Res. Lett., 30, 1505, doi:10.1029/ 2003 GL017172.

, C. J. C. Reason, J. R. E. Lutjeharms, M. Rouault, C. Roy, and S. Masson, 2004: Evolution of interannual warm and cold events in the southeast Atlantic Ocean. J. Climate, 17, 2318-2334, doi:10.1175/1520-0442(2004)017<2318 EOIWAC $>2.0 . \mathrm{CO} ; 2$.
Frankignoul, C., and K. Hasselmann, 1977: Stochastic climate models, part II. Application to sea-surface temperature variability and thermocline variability. Tellus, 29, 289-305, doi:10.1111/j.2153-3490.1977.tb00740.x.

Haarsma, R. J., E. J. D. Campos, and F. Molteni, 2003: Atmospheric response to South Atlantic SST dipole. Geophys. Res. Lett., 30, 1864, doi:10.1029/2003GL017829.

Hagen, E., R. Feistel, J. J. Agenbag, and T. Ohde, 2001: Seasonal and interannual changes in intense Benguela upwelling (1982-1999). Oceanol. Acta, 24, 557-567, doi:10.1016/ S0399-1784(01)01173-2.

Hahn, C. J., and S. G. Warren, 2009: Extended edited synoptic cloud reports from ships and land stations over the globe, 1952-1996. Carbon Dioxide Information Analysis Center Numerical Data Package NDP-026C, 88 pp. [Available online at http://cdiac.ornl.gov/ftp/ndp026c/ndp026c.pdf.]

Hirst, A., and S. Hastenrath, 1983: Atmosphere-ocean mechanisms of climate anomalies in the Angola-tropical Atlantic sector. J. Phys. Oceanogr., 13, 1146-1157, doi:10.1175/1520-0485(1983)013<1146: AOMOCA $>2.0 . \mathrm{CO} ; 2$.

Hisard, P., 1980: Observation de response du type "El Nino" dans l'Atlantique tropical oriental-Golfe de Guinee. Oceanol. Acta, 3, 69-78

Horel, J. D., V. E. Kousky, and M. T. Kagano, 1986: Atmospheric conditions in the Atlantic sector during 1983 and 1984. Nature, 322, 248-251, doi:10.1038/322248a0.

Houghton, R. W., and Y. M. Tourre, 1992: Characteristics of low-frequency sea surface temperature fluctuations in the tropical Atlantic. J. Climate, 5, 765-771, doi:10.1175/ 1520-0442(1992)005<0765:COLFSS $>2.0 . \mathrm{CO} ; 2$.

Kalnay, and Coauthors, 1996: The NCEP/NCAR 40-Year Reanalysis Project. Bull. Amer. Meteor. Soc., 77, 437-471, doi:10.1175/1520-0477(1996)077<0437:TNYRP>2.0.CO;2.

Klein, S. A., and D. L. Hartmann, 1993: The seasonal cycle of low stratiform clouds. J. Climate, 6, 1587-1606, doi:10.1175/ 1520-0442(1993)006<1587:TSCOLS $>2.0 . \mathrm{CO} ; 2$.

—,- , and J. R. Norris, 1995: On the relationships among low-cloud structure, sea surface temperature, and atmospheric circulation in the summertime northeast Pacific. J. Climate, 8, 1140-1155, doi:10.1175/1520-0442(1995)008<1140: OTRALC $>2.0 . \mathrm{CO} ; 2$

Loeb, N. G., B. A. Wielicki, D. R. Doelling, G. L. Smith, D. F. Keyes, S. Kato, N. Manalo-Smith, and T. Wong, 2009: Toward optimal closure of the Earth's top-of-atmosphere radiation budget. J. Climate, 22, 748-766, doi:10.1175/ 2008JCLI2637.1.

Marshall, J., and Coauthors, 2001: North Atlantic climate variability: Phenomena, impacts, and mechanisms. Int. J. Climatol., 21, 1863-1898, doi:10.1002/joc.693.

Medeiros, B., and B. Stevens, 2011: Revealing differences in GCM representations of low clouds. Climate Dyn., 36, 385-399, doi:10.1007/s00382-009-0694-5.

Mehta, V. M., 1998: Variability of the tropical ocean surface temperature at decadal-multidecadal time scales. Part I: Atlantic Ocean. J. Climate, 11, 2351-2375, doi:10.1175/ 1520-0442(1998)011<2351:VOTTOS > 2.0.CO;2.

Merle, J., 1980: Annual and interannual variability of temperature in the eastern equatorial Atlantic Ocean-Hypothesis of an Atlantic El Nino. Oceanol. Acta, 3, 209-220.

Mitchell, T. P., and J. M. Wallace, 1992: On the annual cycle in equatorial convection and sea surface temperature. J. Climate, 5, 1140-1156, doi:10.1175/1520-0442(1992)005<1140: TACIEC $>2.0 . \mathrm{CO} ; 2$ 
Nobre, P., and J. Shukla, 1996: Variations of sea surface temperature, wind stress, and rainfall over the tropical Atlantic and South America. J. Climate, 9, 2464-2479, doi:10.1175/ 1520-0442(1996)009<2464:VOSSTW >2.0.CO;2.

Norris, J. R., 1998: Low cloud type over the ocean from surface observations. Part II: Geographical and seasonal variations. J. Climate, 11, 383-403, doi:10.1175/1520-0442(1998)011<0383: LCTOTO $>2.0 . \mathrm{CO} ; 2$.

_ 2005: Multidecadal changes in near-global cloud cover and estimated cloud cover radiative forcing. J. Geophys. Res., 110, D08206, doi:10.1029/2004JD005600.

Okumura, Y. M., 2013: Origins of tropical Pacific decadal variability: Role of stochastic atmospheric forcing from the South Pacific. J. Climate, 26, 9791-9796, doi:10.1175/ JCLI-D-13-00448.1.

Park, S., C. Deser, and M. A. Alexander, 2005: Estimation of the surface heat flux response to sea surface temperature anomalies over the global oceans. J. Climate, 18, 4582-4599, doi:10.1175/ JCLI3521.1.

Penland, C., and L. Matrosova, 1998: Prediction of tropical Atlantic sea surface temperatures using linear inverse modeling. J. Climate, 11, 483-496, doi:10.1175/1520-0442(1998)011<0483: POTASS $>2.0 . \mathrm{CO} ; 2$.

Robertson, A. W., J. D. Farrara, and C. R. Mechoso, 2003: Simulations of the atmospheric response to South Atlantic sea surface temperature anomalies. J. Climate, 16, 2540-2551, doi:10.1175/1520-0442(2003)016<2540:SOTART $>2.0$.CO;2.

Rossow, W. B., and R. A. Schiffer, 1999: Advances in understanding clouds from ISCCP. Bull. Amer. Meteor. Soc., 80, 2261-2287, doi:10.1175/1520-0477(1999)080<2261:AIUCFI > 2.0.CO;2.

Ruiz-Barradas, A., J. A. Carton, and S. Nigam, 2000: Structure of interannual-to-decadal climate variability in the tropical Atlantic sector. J. Climate, 13, 3285-3297, doi:10.1175/ 1520-0442(2000)013<3285:SOITDC > 2.0.CO;2.

Servain, J., 1991: Simple climatic indices for the tropical Atlantic Ocean and some application. J. Geophys. Res., 96, $15137-$ 15 146, doi:10.1029/91JC01046.

— I. Wainer, J. P. McCreary Jr., and A. Dessier, 1999: Relationships between the equatorial and meridional modes of climatic variability in the tropical Atlantic. Geophys. Res. Lett., 26, 485-488, doi:10.1029/1999GL900014.

Smith, T. M., R. W. Reynolds, T. C. Peterson, and J. Lawrimore, 2008: Improvements to NOAA's historical merged landocean surface temperature analysis (1880-2006). J. Climate, 21, 2283-2296, doi:10.1175/2007JCLI2100.1.

Sterl, A., and W. Hazeleger, 2003: Coupled variability and air-sea interaction in the South Atlantic Ocean. Climate Dyn., 21, 559-571, doi:10.1007/s00382-003-0348-y.

Stevens, B., and S. Bony, 2013: What are climate models missing? Science, 340, 1053-1054, doi:10.1126/science.1237554.

, and Coauthors, 2013: The atmospheric component of the MPI-M Earth system model: ECHAM6. J. Adv. Model. Earth Syst., 5, 146-172, doi:10.1002/jame.20015.
Sutton, R. T., S. P. Jewson, and D. P. Rowell, 2000: The elements of climate variability in the tropical Atlantic. J. Climate, 13, 32613284, doi:10.1175/1520-0442(2000)013<3261:TEOCVI>2.0.CO;2.

Tanimoto, Y., and S.-P. Xie, 2002: Inter-hemispheric decadal variations in SST, surface wind, heat flux and cloud cover over the Atlantic Ocean. J. Meteor. Soc. Japan, 80, 1199-1219, doi:10.2151/jmsj.80.1199.

Taylor, K. E., R. J. Stouffer, and G. A. Meehl, 2012: An overview of CMIP5 and the experiment design. Bull. Amer. Meteor. Soc., 93, 485-498, doi:10.1175/BAMS-D-11-00094.1.

Terray, P., 2011: Southern Hemisphere extratropical forcing: A new paradigm for El Niño-Southern Oscillation. Climate Dyn., 36, 2171-2199, doi:10.1007/s00382-010-0825-z.

Trzaska, S., A. W. Robertson, J. D. Farrara, and C. R. Mechoso, 2007: South Atlantic variability arising from air-sea coupling: Local mechanisms and tropical-subtropical interactions. J. Climate, 20, 3345-3365, doi:10.1175/JCLI4114.1.

Venegas, S. A., L. A. Mysak, and D. N. Straub, 1996: Evidence for interannual and interdecadal climate variability in the South Atlantic. Geophys. Res. Lett., 23, 2673-2676, doi:10.1029/ 96GL02373.

Wagner, R. G., and A. da Silva, 1994: Surface conditions associated with anomalous rainfall in the Guinea coastal region. Int. J. Climatol., 14, 179-200, doi:10.1002/joc.3370140205.

Wang, F., 2010: Thermodynamical coupled modes in the tropical atmosphere-ocean: An analytical solution. J. Atmos. Sci., 67, 1667-1677, doi:10.1175/2009JAS3262.1.

Wood, R., 2012: Stratocumulus clouds. Mon. Wea. Rev., 140, 2373 2423, doi:10.1175/MWR-D-11-00121.1.

Xie, S.-P., and J. A. Carton, 2004: Tropical Atlantic variability: Patterns, mechanisms, and impacts. Earth's Climate: The Ocean-Atmosphere Interaction, Geophys. Monogr., Vol. 147, Amer. Geophys. Union, 121-142.

Zebiak, S. E., 1993: Air-sea interaction in the equatorial Atlantic region. J. Climate, 6, 1567-1586, doi:10.1175/ 1520-0442(1993)006<1567:AIITEA > 2.0.CO;2.

Zelinka, M. D., S. A. Klein, and D. L. Hartmann, 2012: Computing and partitioning cloud feedbacks using cloud property histograms. Part II: Attribution to changes in cloud amount, altitude, and optical depth. J. Climate, 25, 3736-3754, doi:10.1175/ JCLI-D-11-00249.1.

Zhang, H., C. Deser, A. Clement, and R. Tomas, 2014: Equatorial signatures of the Pacific meridional modes: Dependence on mean climate state. Geophys. Res. Lett., 41, 568-574, doi:10.1002/2013GL058842.

Zhang, R., S. M. Kang, and I. M. Held, 2010: Sensitivity of climate change induced by the weakening of the Atlantic meridional overturning circulation to cloud feedback. J. Climate, 23, 378389, doi:10.1175/2009JCLI3118.1.

Zhou, Z., and J. A. Carton, 1998: Latent heat flux and interannual variability of the coupled atmosphere-ocean system. J. Atmos. Sci., 55, 494-501, doi:10.1175/1520-0469(1998)055<0494: LHFAIV $>2.0 . \mathrm{CO} ; 2$. 